\title{
1 Wnt/ $\boldsymbol{\beta}$-catenin regulates alloreactive $\mathbf{T}$ cells for the treatment of hematological malignancies
}

4
Mahinbanu Mammadli*1 ${ }^{1}$, Rebecca Harris* ${ }^{1}$, Sara Mahmudlu ${ }^{1}$, Anjali Verma ${ }^{2}$, Adriana May ${ }^{1}$, Rohan Dhawan ${ }^{1}$, Adam T. Waickman ${ }^{1}$, Jyoti Misra Sen ${ }^{2,3}$, and Mobin Karimi ${ }^{1}$.

${ }^{1}$ Department of Microbiology and Immunology, SUNY Upstate Medical University, Syracuse, NY 13210.

${ }^{2}$ National Institute on Aging-National Institutes of Health, 08C218, Biomedical Research Center, 251 Bayview Boulevard, Suite 100, Baltimore, MD 21224

${ }^{3}$ Immunology Program, Department of Medicine, Johns Hopkins School of Medicine, Baltimore, MD 21224

*MM and RH equally contributed to this work

Conflict of Interest: The authors declare no conflicts of interest.

To whom correspondence should be addressed:

Mobin Karimi

Assistant Professor of Immunology and Microbiology

SUNY Upstate Medical University,

766 Irving Ave Weiskotten Hall Suite 2281,

Syracuse, NY 13210

Office Phone: 315-464-2344

Laboratory Phone: 315-464-7652

Email: karimim@upstate.edu

Abstract words\#191

Total words 5000

Reference\# 57

Figures\# 6

Table 3

Key Points:

- Wnt/ $\beta$-catenin affects T cell migration to GVHD target organs.

- Wnt $/ \beta$-catenin affects $\mathrm{T}$ cell cytokine production in disease model.

- Wnt $/ \beta$-catenin affects $\mathrm{T}$ cell gene expression.

Running title: Wnt/ $\beta$-catenin regulates $\mathrm{T}$ cells during disease. 


\section{Abstract}

42 Allogeneic hematopoietic stem cell transplantation (allo-HSCT) is one of the most widely applied forms of adaptive immunotherapy. Both the detrimental graft-versus-host disease (GVHD) and the beneficial graft-versus-leukemia (GVL) effects occurring after allo-HSCT are largely mediated by alloantigen-reactive donor T cells in the graft. Separating GVHD from GVL effects is a formidable challenge, and a greater understanding of donor T cell biology is required to accomplish the uncoupling of GVHD from GVL. Here, we tested a novel mouse model of transgenic over-expression of human $\beta$-catenin $(\mathrm{Cat}-\mathrm{Tg})$ in an allo-HSCT model. Our data show that T cells from Cat-Tg mice did not cause GVHD. Surprisingly, Cat-Tg T cells maintained the GVL effect. Donor T cells from Cat-Tg mice exhibited significantly lower inflammatory

51 cytokine production and reduced donor $\mathrm{T}$ cell proliferation, while upregulating cytotoxic

52 mediators that resulted in enhanced cytotoxicity. RNA sequencing data revealed changes in the 53 expression of over 150 genes for $\mathrm{CD} 4$, and over 250 genes for $\mathrm{CD}^{+} \mathrm{T}$ cells involved in essential 54 aspects of immune response and GVHD pathophysiology. Transgenic over-expression of human $55 \beta$-catenin primarily affects $\mathrm{CD}^{+} \mathrm{T}$ cell phenotype. Altogether, our data suggest that $\beta$-catenin is 56 a druggable target for developing therapeutic strategies to reduce GVHD while preserving the 57 beneficial GVL effects following allo-HSCT treatment. 


\section{Introduction}

60 Allogeneic hematopoietic stem cell transplantation (allo-HSCT) is a curative treatment for

61 patients with hematological malignancies, due to eradication of host malignant cells by donor $\mathrm{T}$

62 cells (graft-versus-leukemia or GVL) (1). In 40-70\% of patients, the same donor T cells also

63 attack healthy tissues like the gastrointestinal (GI) tract and liver, leading to graft-versus-host

64 disease (GVHD) (2). The mortality rate due to GVHD is higher than $20 \%(3,4)$. Therefore,

65 therapeutic protocols that enhance the control of GVL and diminish the effects due to GVHD are

66 essential for the treatment of leukemia.

$67 \mathrm{Wnt} / \beta$-catenin signaling plays a critical role in $\mathrm{T}$ cell development and tissue homeostasis

68 (5). Wnt/ $\beta$-catenin pathways also play an important role in thymocyte development,

69 differentiation, polarization, and survival of mature T lymphocytes (6). Published data have

70 shown that Wnt/ $\beta$-catenin signaling is a key regulator of $\mathrm{T}$ cell development at various stages of

71 thymocyte differentiation (7). The transcription factor T Cell Factor-1 (TCF-1), encoded by the

72 Tcf7 gene, and Lymphoid Enhancer Binding Factor-1 (LEF-1) are the downstream transcription

73 effectors of the canonical Wnt signaling pathway (8). Both $T c f 7$ and Lefl are highly expressed by

74 naïve $\mathrm{CD}^{+} \mathrm{T}$ cells, and as these cells encounter antigen, the levels of $T c f 7$ and Lefl decrease in

75 these cells (9). There are several lines of evidence suggesting that $\mathrm{Wnt} / \beta$-catenin signaling

76 downregulates production of proinflammatory cytokines (10). These cytokines include IL-1 $\beta$, IL-

$776, \mathrm{IL}-8$, and TNF- $\alpha$. Wnt/ $\beta$-catenin signaling is critical for T cell differentiation, effector

78 functions, and migration (11). The activation of $\beta$-catenin signaling turns $\mathrm{CD}^{+} \mathrm{T}$ cells into Tfh-

79 like cells (12). $\beta$-catenin signaling can also differentiate $\mathrm{CD}^{+} \mathrm{T}$ cells into effector cells (13).

80 There have been also reports that $\mathrm{Wnt} / \beta$-catenin signaling pathways are highly expressed in

81 naive $\mathrm{CD}^{+}$and memory $\mathrm{CD}^{+} \mathrm{T}$ cells, but expressed less in effector $\mathrm{CD}^{+} \mathrm{T}$ cells (11). Since 
82 the activation and maintenance of $\mathrm{T}$ cells are both required for anti-tumor immunity (GVL) and

83 GVHD, we hypothesized that Wnt/ $\beta$-catenin signaling may play an important role in these linked

84 processes.

85 In this study, we used a novel mouse model expressing transgenic $\beta$-catenin, $(\mathrm{Cat}-\mathrm{Tg}$

86 mice, ) that enhances the expression of the protein by 2-3 fold (8). We demonstrate that donor $\mathrm{T}$

87 cells from $\mathrm{Cat}$ - $\mathrm{Tg}$ mice do not induce GVHD in an MHC-mismatched mouse model, but still

88 clear primary B-cell acute lymphoblastic leukemia (B-ALL) cells (14, 15). Our data also showed

89 that Cat-Tg mice had fewer naïve $\mathrm{CD}^{+} \mathrm{T}$ cells and an increase in T cells with an activated

90 phenotype that may trend towards exhaustion. Interestingly, our data show that recipient mice

91 allogeneically transplanted with $\mathrm{T}$ cells from $\mathrm{Cat}-\mathrm{Tg}$ mice had significantly decreased

92 proinflammatory cytokines in serum, and the donor T cells showed lower levels of expansion.

93 Unbiased analysis of gene expression using RNA sequencing showed that transgenic expression

94 of $\beta$-catenin affected pathways like regulation of immune system processes, , cell activation,

95 lymphocyte activation, adaptive immune response, lymphocyte mediated immunity, MHC

96 complex, cytokine production, TCR signaling pathways, T cell and B cell activation, T cell

97 proliferation, Th1/Th2 cell differentiation, Th17 cell differentiation, signaling (NF- $\kappa \beta$, TNF, PLC-

$98 \gamma 2$, BLNK and others), GVHD, Allograft rejection, Autoimmunity, cell adhesion, and chemokine

99 receptors in $\mathrm{CD}^{+}$and $\mathrm{CD}^{+} \mathrm{T}$ cells. We also observed that the similar pathways along with

100 Hematopoietic cell lineage, GVHD, Allograft rejection, Th1, Th2, Th17 differentiation and other

101 pathways was differentially regulated in $\mathrm{CD}^{+} \mathrm{T}$ by $\beta$-catenin over-expression. Importantly,

102 trafficking of donor T cells to GVHD target organs is considered a hallmark of GVHD(16). Our

103 data showed that transgenic expression of $\beta$-catenin specifically affects genes for cell

104 chemotaxis, chemokine receptors, cell adhesion molecules, and cell migratory molecules. We 
105 confirmed the existence of a migration defect and examined tissue damage to target organs using

106 histology. In summary, we provide a mechanistic understanding of the manner in which

107 enhancement of the Wnt/ $\beta$-catenin-TCF1/LEF1 pathway protects from GVHD while maintaining

108 GVL. Thus, we have shown that $\beta$-catenin and Wnt signaling are potential druggable targets to

109 separate GVHD and GVT to improve allo-HSCT outcomes.

110 T cells from Cat-Tg mice have an activated phenotype. Both $\mathrm{CD}^{+}$and $\mathrm{CD} 4^{+} \mathrm{T}$ cells from

111 Cat- $\mathrm{Tg}$ mice showed higher expression of $\mathrm{CD} 44$, and only in $\mathrm{CD}^{+} \mathrm{T}$ cells, higher expression of

112 CD122 and Eomes, with no difference in T-bet expression. CD4 ${ }^{+}$T cells from Cat-Tg mice have

113 significantly higher expression of PD-1, but no differences in CTLA-4 or TCF-1 expression.

$114 \mathrm{CD}^{+} \mathrm{T}$ cells from $\mathrm{Cat}-\mathrm{Tg}$ mice also showed a trend towards increased expression of PD-1, but

115 no difference in CTLA-4 or TCF-1 expression. Our data showed that there were less naïve and

116 more central memory cells among $\mathrm{CD}^{+} \mathrm{T}$ cells from $\mathrm{Cat}-\mathrm{Tg}$ mice. We observed that there were

117 similar trends in $\mathrm{CD}^{+} \mathrm{T}$ cells from $\mathrm{Cat}-\mathrm{Tg}$ mice, but these differences were not significant

118 compared to $\mathrm{CD}^{+}{ }^{\mathrm{T}}$ cells from WT mice- $\mathrm{Tg}$ mice, but there were no significant differences

119 compared to $\mathrm{CD}^{+}{ }^{\mathrm{T}}$ cells from WT mice.

120 We also found that $\mathrm{T}$ cells from $\mathrm{Cat}-\mathrm{Tg}$ mice express more perforin and granzyme

121 B than T cells from WT mice, showing that T cells from Cat-Tg mice have better cytotoxic

122 function compared to T cells from WT mice. Next, we examined whether donor T cells from

123 Cat-Tg mice had differences in serum cytokines post allo-HSCT. Our data show that recipient

124 mice allogeneically transplanted with T cells from Cat-Tg mice had significantly decreased

125 proinflammatory cytokines in the serum. On a cellular level, both CD ${ }^{+}$and CD $4^{+}$donor $\mathrm{T}$ cells

126 from Cat-Tg mice expressed less IFN- $\gamma$, but had no difference in TNF- $\alpha$ compared to WT cells.

127 We have also shown that both $\mathrm{CD}^{+}$and $\mathrm{CD}^{+} \mathrm{T}$ cells from $\mathrm{Cat}-\mathrm{Tg}$ mice trend towards 
128 proliferating less than donor T cells from WT mice, but this effect was not statistically

129 significant. Next, we examined TCR signaling and we did not observe any differences in PLC-

$130 \gamma 1$, ERK, or IRF-4 total protein level.

131 To investigate the transcriptomic changes from $\beta$-catenin over-expression in $\mathrm{T}$ cells, we

132 performed RNA sequencing as an unbiased approach to examine the mechanism behind the

133 observed changes in T cell function and phenotype. Our data showed that on a transcriptomic

134 level, pathways like regulation of immune system processes, defense responses, T cell and B cell

135 activation, $\mathrm{T}$ cell proliferation, adaptive immune responses, immune system development,

136 inflammatory responses, cytokine production, signaling (NF- $\kappa \beta$, TNF, PLC- $\gamma 2$, BLNK and others),

137 cell adhesion, and chemokine receptors in $\mathrm{CD}^{+} \mathrm{T}$ cells are significantly affected by $\beta$-catenin

138 over-expression. We also observed that similar pathways, along with hematopoietic cell lineage,

139 GVHD, allograft rejection, Th1, Th2, Th17 differentiation, and other pathways were

140 differentially regulated in $\mathrm{CD}^{+} \mathrm{T}$ cells with $\beta$-catenin over-expression.

141 Trafficking of donor T cells to GVHD target organs is considered a hallmark of GVHD

142 (17). Our data showed that $\beta$-catenin specifically affects genes for cell chemotaxis, chemokine

143 receptors, cell adhesion molecules, and cell migratory molecules. Finally, we have shown that

$144 \mathrm{CD}^{+}$donor T cells from $\mathrm{Cat}-\mathrm{Tg}$ mice have altered $\mathrm{T}$ cell proliferation. Both functional and

145 genetic data show that $\mathrm{T}$ cells from $\mathrm{Cat}-\mathrm{Tg}$ mice have differences in migration, chemokine

146 receptor activity, chemotaxis and cell adhesion molecules of $\mathrm{CD}^{+} \mathrm{T}$ cells. Even though we saw

147 significant differences in genes involved in these pathways in $\mathrm{CD}^{+} \mathrm{T}$ cells, the number of genes

148 involved was less than in $\mathrm{CD}^{+} \mathrm{T}$ cells. We also did not observe any functional migration defect

149 in $\mathrm{CD}^{+} \mathrm{T}$ cells. 
150 For the first time, we have provided evidence that $\beta$-catenin has a significant impact on $\mathrm{T}$

151 cell functions in a disease model. This effect is due to changes in T cell phenotype, function, and

152 gene expression. Thus, we have shown that $\beta$-catenin and Wnt signaling are potential druggable

153 targets to separate GVHD and GVT to improve allo-HSCT outcomes. 


\section{Materials and Methods}

\section{Mice}

156 Cat-Tg mice were described previously (18). C57BL/6, C57BL/6.SJL (B6-SJL), B6-Ly5.1

157 (B6.SJL-Ptprc ${ }^{\mathrm{a}} \mathrm{Pepc}^{\mathrm{b}} / \mathrm{BoyCrl}$ ) and BALB/c mice were purchased from Charles River or Jackson

158 Laboratory. Mice aged 8-12 weeks were used, and all experiments were performed with age and

159 sex-matched mice. Animal maintenance and experimentation were performed in accordance with

160 the rules and guidance set by the institutional animal care and use committees at SUNY Upstate

161 Medical University.

162

163 Reagents, cell lines, flow cytometry.

164 Monoclonal antibodies were purchased from Biolegend or eBioscience and were used at 1:100

165 dilution. Antibodies used included mouse anti-CD3(cat\#100102), anti-CD28(cat\# 102116), anti-

166 CD3 BV605, anti-CD4-PE, anti-CD8-Pe/Cy7, anti-Eomes-Pe/Cy7, anti-CD44-Pacific Blue, anti

167 CD122-APC, anti-CD62L- APC/Cy7, anti-T-bet-BV421, anti-CTLA4-PE, anti-PD1- BV785,

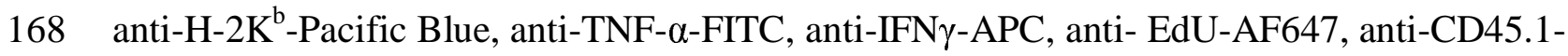

169 FITC, anti-CD122-APC, anti-TCF-1-PE anti-CD45.2 APC. We performed multiplex ELISAs

170 using the Biolegend LEGENDplex Assay Mouse Th Cytokine Panel kit (741043). D-Luciferin

171 was purchased from Gold Bio (St Louis MO). Flow cytometry was performed on a BD LSR

172 Fortessa (BD Biosciences). Data were analyzed with FlowJo software (Tree Star, Ashland, OR).

173 For cell sorting, T cells were purified with anti-CD90.2, or anti-CD4 and anti-CD8

174 magnetic beads using MACS columns (Miltenyi Biotec, Auburn, CA) prior to cell surface

175 staining. FACS sorting was performed with a BD FACS Aria IIIu cell sorter (BD Biosciences).

176 Cells were sorted into sorting media (50\% FBS in RPMI) for maximum viability, or Trizol for 
177 RNAseq experiment. FACS-sorted populations were typically of $>95 \%$ purity. All cell culture

178 reagents and chemicals were purchased from Invitrogen (Grand Island, NY) and Sigma-Aldrich

179 (St. Louis, MO), unless otherwise specified. For signaling analysis, antibodies against PLC $\gamma 1$,

180 ERK, IRF-4, Granzyme, Perforin, and $\beta$-Actin (total) were purchased from Cell Signaling

181 Technology (Danvers, MA). The primary mouse B-ALL blasts cells (15) were transduced with

182 luciferase, and cultured as described previously (19).

183

184 Allo-HSCT and GVL studies

185 Lethally irradiated BALB/c mice ( $800 \mathrm{cGy}$, split into 2 doses of $400 \mathrm{cGy}$ with 12 hours interval

186 between) were injected intravenously with $10 \times 10^{6} \mathrm{~T}$ cell-depleted bone marrow ( $\left.\mathrm{TCD} \mathrm{BM}\right)$ cells

187 with or without $1 \times 10^{6}$ MACS purified CD3 ${ }^{+} \mathrm{T}$ cells. Donor T cells were taken from WT

188 (C57B1/6), WT Ly5.1 (B6.SJL-Ptprc ${ }^{\mathrm{a}}$ Pepc $\left.^{\mathrm{b}} / \mathrm{BoyCrl}\right)$, or Cat-Tg mice. For GVL experiments, $B$ -

189 cell acute lymphoblastic leukemia (B-ALL) primary blasts $(14,15)$ transduced with luciferase

190 were cultured as described previously, and 1 X10 $0^{5}$ luciferase-expressing B-ALL blasts cells were

191 used. Mice were evaluated once a week from the time of leukemia cell injection for more than 60

192 days post-transplant by bioluminescence imaging using the IVIS 200 Imaging System (Xenogen)

193 (19). Clinical presentation of the mice was assessed 3 times per week by a scoring system that

194 sums changes in 6 clinical parameters (for each parameter score was ranged from 0-2): posture,

195 activity, fur texture, diarrhea, weight loss, and skin integrity (20). Mice were euthanized if they

196 lost $\geq 30 \%$ of their initial body weight or became moribund.

197

198 Cytokine production, cytotoxicity, and Edu incorporation assays. 
199 On Day 7 post-transplantation, serum from cardiac blood and single cell suspensions of 200 splenocytes were obtained from allo-transplanted recipients. Serum IFN- $\gamma$, TNF- $\alpha$, IL-5, IL-12,

201 IL-6, IL-10, IL-9, IL-17A, IL-17F, IL-22, and IL-13 levels were determined by multiplex

202 cytokine assays (Biolegend LEGENDplex)(15, 21). Splenocytes taken from allo-transplanted

203 recipients were stimulated with anti-CD3/anti-CD28 $(2.5 \mathrm{ug} / \mathrm{ml})$ for 6 hours in the presence of

204 Golgiplug (BD Cytofix/Cytoperm Plus kit cat\#555028) (1:1000). After incubation, the cells were

205 fixed then permeabilized and stained intracellularly for cytokines (IFN- $\gamma$ and TNF- $\alpha$ ).

206 For the proliferation assay, recipient BALB/c mice were transplanted as described above

$207\left(1 \times 10^{6} \mathrm{CD}^{+}\right.$donor T cells and $\left.10 \mathrm{X} 10^{6} \mathrm{WT}{ }_{\mathrm{TCD}} \mathrm{BM}\right)$, and recipient mice were injected at day 5-6

208 with 25mg/kg EdU (20518 from Cayman Chemicals) in PBS. At day 7, the recipient mice were

209 euthanized and lymphocytes from spleen were obtained. Cells were processed and stained using

210 an EdU click chemistry kit (C10424 from Invitrogen), and also stained for H2Kb, CD3, CD4,

211 and CD8 to identify donor cells as perversely described (22).

212 For cytotoxicity assays, luciferase-expressing B-ALL cells were seeded in 96-well flat

213 bottom plates at a concentration of $3 \times 10^{5}$ cells $/ \mathrm{ml}$. D-firefly luciferin potassium salt $(75 \mu \mathrm{g} / \mathrm{ml}$;

214 Caliper Hopkinton, MA) was added to each well and bioluminescence was measured with the

215 IVIS-50 Imaging System. Subsequently, effector cells (MACS-purified) were added at 40:1,

$21620: 1$, and 10:1 effector-to-target (E:T) ratios and incubated at $37^{\circ} \mathrm{C}$ for 4 hours. Bioluminescence

217 in relative luciferase units (RLU) was then measured for 1 minute. Cells treated with RIPA lysis

218 buffer was used as a measure of maximal killing. Target cells incubated without effector cells

219 were used to measure spontaneous death. Triplicate wells were averaged and percent lysis was

220 calculated from the data using the following equation: $\%$ specific lysis $=100 \mathrm{X}$ (spontaneous

221 death RLU-test RLU)/(spontaneous death RLU- maximal killing RLU) (23) 


\section{Migration assays}

223 Lethally irradiated BALB/c mice were injected intravenously with $10 \mathrm{X} 10^{6} \mathrm{WT}$ T cell-depleted

224 bone marrow ( $\mathrm{TCD} B M)$, and a 1:1 mixture of WT (B6-Ly5.1) CD45.1 ${ }^{+}$MACS-purified CD8 ${ }^{+}$and $225 \mathrm{CD}^{+} \mathrm{T}$ cells (checked for 1:1 ratio with flow) with either WT (C57BL/6) CD45.2 ${ }^{+}$cells or Cat$226 \mathrm{Tg}$ CD45.2 $2^{+}$cells (total $1 \times 10^{6}$ cells). The donor cells were checked pre-transplant for a 1:1 ratio 227 of donor types, and a 1:1 ratio of CD4:CD8 T cells within each donor type. Seven days post228 transplantation, the mice were sacrificed and lymphocytes from the liver, small intestine, and 229 spleen were isolated. Livers were perfused with PBS, dissociated, and filtered with a 70 $\mu \mathrm{m}$ filter. 230 The small intestines were washed in media, shaken in strip buffer at $37^{\circ} \mathrm{C}$ for 30 minutes to 231 remove the epithelial cells, and then washed, before digesting with collagenase D (100 mg/ml) 232 and DNase $(1 \mathrm{mg} / \mathrm{ml})$ for 30 minutes in $37^{\circ} \mathrm{C}$, and followed by filtering with a $70 \mu \mathrm{m}$ filter.

233 Lymphocytes from the liver and intestines were further enriched using a $40 \%$ Percoll gradient. 234 The cells were analyzed for $\mathrm{H} 2 \mathrm{~K}^{\mathrm{b}}, \mathrm{CD} 45.1^{+}$and $\mathrm{CD} 45.2^{+}, \mathrm{CD}^{+}, \mathrm{CD}^{+}$and $\mathrm{CD} 4^{+}$by flow 235 cytometry as described before $(15,21)$.

\section{RNA sequencing}

2383 Recipient BALB/c mice for each group were short-term transplanted as described above $239\left(1 \times 10^{6} \mathrm{CD}^{+}\right.$donor $\mathrm{T}$ cells and $\left.10 \times 10^{6} \mathrm{WT}{ }_{\mathrm{TCD}} \mathrm{BM}\right)$, and at day 7 , recipient mice were 240 euthanized and splenocytes were obtained for post-transplant samples. $3 \mathrm{WT}$ or $\mathrm{Cat}$-Tg mice also 241 were euthanized and fresh splenocytes were isolated for pre-transplanted samples. CD4 ${ }^{+}$and $242 \mathrm{CD}^{+} \mathrm{T}$ cells from each pre- and post-transplanted mouse were FACS sorted as described above. 243 These cells were all sorted into Trizol and brought to the Molecular Analysis Core (SUNY 244 Upstate) https://www.upstate.edu/research/facilities/molecular-analysis.php for RNA extraction 
245 and library prep, followed by RNA sequencing analysis at the University at Buffalo Genomics

246 Core http://ubnextgencore.buffalo.edu. We generated RNA sequencing data from four groups for

247 each cell subset (CD4/CD8): WT-pre tx and Cat-Tg pre tx cells (prior to transplantation); and

248 WT-Day7 tx, Cat-Tg Day-7 tx (7 days post-transplantation). We were unable to sort enough

249 donor $\mathrm{T}$ cells from small intestines and liver of the recipient mice that received $\mathrm{Cat}-\mathrm{Tg} \mathrm{CD}^{+} \mathrm{T}$

250 cells. All data were processed and analyzed using the R programming language (Version 4.0.4),

251 the RStudio interface (Version 1.4.1106), and Bioconductor. For pseudoalignment and gene

252 expression transcript abundance of samples was computed by pseudoalignment with

253 Kallisto $_{41}($ version 0.46.2). Transcript per million (TPM) values were then normalized and fitted

254 to a linear model by empirical Bayes method with the Voom and Limma R packages $(24,25)$ and

255 differential gene expression was defined as a Benjemini and Hochberg adjusted $p$-value-False

256 Discovery Rate (FDR) of $\square<\square 0.1$. For functional enrichment analysis, the g: Profiler (26)

257 toolset, g:GOSt tool was used to illustrate Manhattan plot. Gene Set Enrichment Analysis

258 (GSEA) was performed against the Molecular Signatures Database (MSigDB)(27) using the

259 Hallmark pathways collection. Data will be deposited (https://www.ncbi.nlm.nih.gov/geo/). The

260 RNAseq experiment described here was performed as part of the experiment described in other

261 recent publications from our lab $(15,28)$. Therefore, the data generated for WT pre- and post-

262 transplanted samples (CD4 and CD8) is the same as that shown in the papers mentioned, but here

263 these data are compared to data for Cat-Tg mice.

\section{Western blotting}

265 Cells were lysed in freshly prepared lysis buffer (RIPA buffer (Fisher Scientific cat\#PI89900) + 266 cOmplete protease inhibitor cocktail (Sigma Aldrich cat\#11697498001) and centrifuged at 14000

$267 \mathrm{rpm}$ for 10 minutes at $4^{\circ} \mathrm{C}$. Aliquots containing $1 \mathrm{X} 10^{6}$ cells were separated on $12-18 \%$ 
268 denaturing polyacrylamide gel and transferred to nitrocellulose membranes for immunoblot

269 analysis using specific Abs.

270 Histopathological Evaluation

271 Lethally irradiated recipient mice were transplanted with $10 \times 10^{6} \mathrm{~T}$ cell-depleted bone marrow

272 cells, and $1 \mathrm{X} 10^{6} \mathrm{CD}^{+} \mathrm{T}$ cells from WT or $\mathrm{Cat}-\mathrm{Tg}$ mice. At day 7 post-transplantation, recipient

273 mouse livers and smalls intestine were obtained and fixed in $10 \%$ neutral buffered formalin, then

274 were sectioned and stained with H\&E by the Histology Core at Cornell University

275 (https://www.vet.cornell.edu/animal-health-diagnostic-center/laboratories/anatomic-

276 pathology/services). Obtained tissues were graded for GVHD by a pathologist (A.M), who was

277 blinded to the study group and disease status. Links for grading criteria:

278 http://surgpathcriteria.stanford.edu/transplant/skinacutegvhd/printable.html,

279 http://surgpathcriteria.stanford.edu/transplant/giacutegvhd/printable.html,

280 http://surgpathcriteria.stanford.edu/transplant/livergvhd/printable.html. Statistical analysis was

281 performed using Mann-Whitney U test.

282

283 Statistics.

284 All numerical data are reported as means with standard deviation unless otherwise noted in

285 figure legends. Data were analyzed for significance with GraphPad Prism v7. Differences were

286 determined using one-way or two-way ANOVA and Tukey's multiple comparisons tests, chi-

287 square test or with a student's t-test when necessary. We used Mann Whitney U test for analysis

288 of GVHD grades. P-values less than or equal to 0.05 are considered significant. All transplant

289 experiments are done with $\mathrm{N}=3$ mice per group, and repeated at least twice, according to power

290 analyses unless otherwise specified. Mice are sex-matched, and age-matched as closely as

291 possible. 


\section{Results}

\section{Donor T cells from Cat-Tg mice do not induce GVHD but maintain GVL function.}

294 To determine whether mouse over-expression of $\beta$-catenin impacts GVHD pathogenesis after

295 allo-HSCT, we examined the effects of $\beta$-catenin signaling on donor $\mathrm{CD}^{+}$and $\mathrm{CD} 8^{+} \mathrm{T}$ cells in

296 an allotransplant model, using C57Bl/6 background mice (MHC haplotype ${ }^{\mathrm{b}}$ ) as donors and

297 BALB/c mice (MHC haplotype ${ }^{\mathrm{d}}$ ) as recipients (15) . To induce GVHD, we used MHC-

298 mismatched donors and recipients. T cell-depleted bone marrow cells from WT mice, and T cells

299 from C57BL/6 (B6) WT or Cat-Tg mice were injected into irradiated BALB/c mice along with

300 luciferase-expressing B-cell acute lymphoblastic leukemia (B-ALL-luc) tumor cells (14, 15) .

301 Lethally irradiated BALB/c mice were injected intravenously with $10 \mathrm{X} 10^{6}$ wild-type (WT) T

302 cell-depleted donor BM cells along with $1 \mathrm{X} 10^{6} \mathrm{MACS}$-sorted donor $\mathrm{CD}^{+} \mathrm{T}$ cells along with

$3031 \mathrm{X} 10^{5} \mathrm{~B}-\mathrm{ALL}-l u c$ blast cells as described $(14,15,21)$. Recipient BALB/c mice were monitored

304 for cancer cell growth using IVIS bioluminescence imaging for over 60 days (Fig. 1A)(15, 21).

305 While leukemia cell growth was observed in mice given bone marrow without T cells, leukemia

306 cell growth was not seen in mice transplanted with T cells from either WT or Cat-Tg mice. As

307 expected, mice transplanted with WT T cells cleared the leukemia cells (Fig. 1A) but suffered

308 significantly from GVHD (Fig 1B-D). In contrast, mice transplanted with Cat-Tg T cells cleared

309 the leukemia cells (Fig. 1A) and displayed minimal signs of GVHD (Fig. 1B-D). All animals

310 transplanted with Cat-Tg T cells survived for more than 65 days post-allo-HSCT (Fig. 1B), with

311 significantly reduced weight loss and clinical scores compared to those transplanted with WT T

312 cells (scored based on weight loss, posture, activity, fur texture, and skin integrity, and diarrhea

313 as previously described) (20), (Fig. 1C-D). Quantification of tumor bioluminescence showed

314 that mice given WT or Cat-Tg T cells cleared the tumor cells, while tumor burden remained high 
315 for mice only given bone marrow (Fig. 1E). Our results indicate that donor T cells from $\mathrm{Cat}-\mathrm{Tg}$

316 mice are dispensable for anti-leukemia immunity, but required for GVHD damage.

318 Wnt/ $\beta$-catenin affects $\mathbf{T}$ cell phenotype and cytotoxic function.

319 To examine how the over-expression of $\mathrm{Wnt} / \beta$-catenin affects $\mathrm{T}$ cell phenotype, we MACS-

320 purified T cells from Cat-Tg WT mice by CD90.2-positive selection. We examined the effects of

$321 \mathrm{Wnt} / \beta$-catenin over-expression on $\mathrm{CD}^{+}$and $\mathrm{CD}^{+} \mathrm{T}$ cells in comparison to $\mathrm{T}$ cells from WT

$322 \mathrm{C} 57 \mathrm{~B} 1 / 6$ mice. Our data showed that $\mathrm{CD}^{+} \mathrm{T}$ cells from Cat-Tg mice exhibit an innate memory

323 phenotype (IMP) $(15,29)$, as indicated by expression of high levels of CD44, CD122, and a key

324 transcription factor Eomesodermin (Eomes). We did not observe any changes in T-bet

325 expression. $\mathrm{CD}^{+} \mathrm{T}$ cells from $\mathrm{Cat}-\mathrm{Tg}$ mice showed a trend towards increased levels of PD-1,

326 but had no differences in CTLA-4 expression compared to CD8 ${ }^{+} \mathrm{T}$ cells WT mice. We also did

327 not observe significant differences in TCF-1 expression (Fig. 2A-D). Next, we examined the

328 effect of $\mathrm{Wnt} / \beta$-catenin on $\mathrm{CD}^{+} \mathrm{T}$ cells. Our data show that $\mathrm{CD}^{+} \mathrm{T}$ cells from $\mathrm{Cat}-\mathrm{Tg}$ mice also

329 express higher levels of CD44 but had no differences in CD122, Eomes, or T-bet expression

330 compared to $\mathrm{CD}^{+} \mathrm{T}$ cells from WT mice. $\mathrm{CD}^{+} \mathrm{T}$ cells from $\mathrm{Cat}-\mathrm{Tg}$ mice also express

331 significantly higher percentage of PD-1 but have no differences in CTLA-4 or TCF-1 compared

332 to $\mathrm{CD}^{+}{ }^{\mathrm{T}}$ cells from WT mice (Fig. 2C-D). Our data shows that $\mathrm{CD}^{+}{ }^{+} \mathrm{T}$ cells from $\mathrm{Cat}-\mathrm{Tg}$ mice

333 were no difference compared to $\mathrm{CD}^{+}$from WT mice. observed in effector memory or

334 transitional to activation state (Fig.2 E) (Supp. Fig.1A). Next, we examined whether CD ${ }^{+} \mathrm{T}$

335 cells from Cat-Tg mice have changes in memory subsets. We observed a significant decrease in

336 naïve CD8+ T cells, no significant differences in the transitioning/activating cells, but

337 significantly increased central memory $\mathrm{CD}^{+} \mathrm{T}$ cells. No significant differences in effector 
memory $\mathrm{CD} 8^{+}$cells from $\mathrm{Cat}-\mathrm{T} g$ mice compared to $\mathrm{CD} 8^{+} \mathrm{T}$ cells from WT mice was observed

339

340

341

342

343

344

345

346

347

\section{(Fig. 2F) (Supp. Fig.1B).}

To examine whether T cells from Cat-Tg mice have cytotoxic function, we purified $\mathrm{CD}^{+}$ T cells from Cat-Tg mice and WT mice, and performed a western blot on the cell lysates. Our western data show that $\mathrm{CD}^{+} \mathrm{T}$ cells from $\mathrm{Cat}-\mathrm{Tg}$ mice express significantly higher levels of granzyme $\mathrm{B}$ and perforin than $\mathrm{CD}^{+} \mathrm{T}$ cells from WT mice (Fig. 2G-I). We quantified the band integrated density and normalized it to $\beta$-actin using Image Lab software (Fig. 2H-I). Next, we examined whether $\mathrm{CD} 8^{+} \mathrm{T}$ cells from $\mathrm{Cat}-\mathrm{Tg}$ mice could mount a cytotoxic response, using a cytotoxicity assay against primary B-ALL cells in different effector to target ratios $(14,15,21)$.

We found that $\mathrm{CD} 8^{+} \mathrm{T}$ cells from $\mathrm{Cat}-\mathrm{Tg}$ mice effectively killed significantly more primary leukemia cells in vitro than $\mathrm{CD}^{+}{ }^{+} \mathrm{T}$ cells from WT mice (Fig. 2J). Our findings demonstrate that $\mathrm{CD} 8^{+} \mathrm{T}$ cells from Cat-Tg mice have enhanced activation markers, significantly altered $\mathrm{CD} 8^{+} \mathrm{T}$ cells phenotype, enhanced expression of Granzyme B and Perforin, and exert better cytotoxicity against primary leukemia cells than $\mathrm{CD} 8^{+} \mathrm{T}$ cells from WT mice.

\section{Wnt/ß-catenin over-expression results in reduced cytokine production and donor $\mathbf{T}$ cell} proliferation without affecting TCR signaling.

The conditioning regimen for allo-HSCT elicits an increase in the production of inflammatory cytokines by donor $\mathrm{T}$ cells, known as a "cytokine storm" $(30,31)$. This is considered one of the hallmarks of GVHD pathogenesis (32). We assessed cytokine production by Cat-Tg T cells in our allo-HSCT model $(\mathrm{B} 6 \rightarrow \mathrm{BALB} / \mathrm{c})$ by examining the levels of serum inflammatory cytokines. We observed that recipient $\mathrm{BALB} / \mathrm{c}$ mice treated with $\mathrm{CD}^{+} \mathrm{T}$ cells from $\mathrm{Cat}-\mathrm{Tg}$ mice expressed significantly less IFN- $\gamma$, TNF- $\alpha$, IL-5, IL-2, IL-6, IL-10 and IL-22 in serum compared to 
361 recipient BALB/c treated with $\mathrm{CD}^{+} \mathrm{T}$ cells from WT mice (Fig. 3A). We did not observe

362 differences in IL-4, IL-9, IL-17A, IL-17F, and IL-13 on day 7 post allotransplantation (Fig. 3A).

363 We also examined donor $\mathrm{CD}^{+}$or $\mathrm{CD}^{+} \mathrm{T}$ cells from secondary lymphoid organs of recipients

364 using anti-H2 $\mathrm{K}^{\mathrm{b}}$ antibodies $\left(\mathrm{H} 2 \mathrm{~K}^{\mathrm{b}}\right.$ is expressed by donor $\mathrm{C} 57 \mathrm{~B} 1 / 6$ cells). Ex vivo donor T cells

365 were cultured for 6 hours with GolgiPlug and stimulated with anti-CD3/CD28 antibodies (Fig.

366 3B-C) or left unstimulated, followed by analysis of IFN- $\gamma$ and TNF- $\alpha$ cytokine production. Cat-

$367 \mathrm{Tg} \mathrm{CD}^{+}$or $\mathrm{CD}^{+} \mathrm{T}$ cells produced significantly less inflammatory IFN- $\gamma$ when stimulated via

368 anti CD3/CD28 antibodies, but we did not observe any differences in TNF- $\alpha$ expression (Fig.

369 3B-E).

370 We next examined donor T cell proliferation using an EdU incorporation assay. We

371 utilized short term allo-transplantation as described above, and recipient were injected with EdU

372 in PBS on day 5 and 6 post-transplant. Seven days post allo-transplantation, splenocytes were

373 obtained from recipients, and donor cells (identified by $\mathrm{H} 2 \mathrm{~K}^{\mathrm{b}+}, \mathrm{CD}^{+}$and $\mathrm{CD} 4^{+}$or $\mathrm{CD} 8^{+}$) were

374 examined for proliferation by EdU incorporation. Both donor $\mathrm{CD}^{+}$and $\mathrm{CD}^{+} \mathrm{T}$ cells from Cat-

$375 T g$ mice showed a trend toward reduced proliferation compared to donor T cells from WT mice,

376 but this effect was not significant (Fig. 3F-H).

377 We have recently shown that modulating TCR signaling through ITK causes T cells to

378 acquire an innate-like memory phenotype (IMP), distinguished by higher expression of CD44,

379 CD122 and Eomes due attenuated TCR signaling (15, 21, 29), Modulation of ITK also affects

380 ERK, PLC $\gamma$-1 and IRF-4 expression level(15). We did not observe significant differences in any

381 of these signaling molecules on T cells from Cat-Tg or WT mice (Fig. 3I-J). Our data suggest

382 that $\mathrm{T}$ cells from $\mathrm{Cat}-\mathrm{Tg}$ mice leads to reduced inflammatory cytokine production and reduced

383 proliferation of allogeneically transplanted T cells in a major mismatch model. Our data also 
384 show that over-expression of $\mathrm{Wnt} / \beta$-catenin does not attenuate TCR signaling. These findings support our observations that GVHD severity is reduced by over-expression of $\beta$-catenin.

Wnt/ $\beta$-catenin expression regulates gene expression in $\mathbf{T}$ cells during GVHD. As an

388 unbiased approach to further explore differences between $\mathrm{CD} 4^{+}$or $\mathrm{CD}^{+} \mathrm{T}$ cells from $\mathrm{WT}$ and

389 Cat-Tg mice, we employed RNA sequencing analysis. We examined the differences in gene

390 expression between WT and $\mathrm{Cat}_{-\mathrm{Tg}} \mathrm{CD}^{+}$and $\mathrm{CD}^{+}{ }^{\mathrm{T}}$ cells before and following allo-HSCT.

391 We sort-purified donor WT and Cat-Tg $\mathrm{CD}^{+}$or $\mathrm{CD}^{+} \mathrm{T}$ cells from freshly isolated splenocytes,

392 and called these pre-transplanted cells (pre-tx). We also MACS purified CD ${ }^{+}$T cells from WT

393 or Cat-Tg mice and transplanted them along with T cell-depleted bone marrow cells into the tail

394 vein of lethally irradiated BALB/c recipients. At day 7 post-transplantation, we sort-purified

395 donor WT and Cat-Tg CD4 ${ }^{+}$or $\mathrm{CD}^{+} \mathrm{T}$ cells (using $\mathrm{H}-2 \mathrm{~K}^{\mathrm{b}}$ antigen expressed by donor $\mathrm{T}$ cells)

396 from recipients, and called these post-transplant day 7 samples (Day 7-tx). The cells were sorted

397 into Trizol reagent and transcriptionally profiled. Principal component analysis (PCA) of CD4 ${ }^{+} \mathrm{T}^{-}$

398 cells identified four clusters of samples, which clearly separated the pre-transplanted WT or Cat-

$399 T g$ and post-transplanted WT or Cat-Tg populations along PC1 (39.5\%) and PC2 (17\%) (Fig.

400 4A). Further analysis of these cell populations identified $\sim 150$ differentially expressed genes

401 (DEGs; FDR <0.1) between WT and Cat-Tg (Supplementary Table 1), of which 74 genes were

402 downregulated and 76 genes were upregulated. These genes were plotted on a volcano plot (Fig.

403 4B). The use of a Spearman correlation method associated with hierarchical clustering of $\mathrm{CD}^{+} \mathrm{T}^{-}$

404 cell samples showed that the WT and Cat-Tg post-transplant samples were most similar (while

405 still clustering separately). Cat-Tg pre-transplant samples were also more similar to post-

406 transplant samples than the WT pre-transplant samples were (Fig 4C). DEGs between WT and

407 Cat- $T g$ in $\mathrm{CD}^{+} \mathrm{T}$ cells were averaged by group and gene co-regulation was determined by 
408 hierarchical clustering, using Pearson correlation with a grouping cutoff $(k)$ of 4 . Each generated 409 module contributed to the different pathway enrichment. Gene expression is averaged by group

$410 \quad(n \square=\square 3$ ) for clarity and displayed as $z$ score across each row (Fig. 4C). Functional pathway

411 analysis of these genes revealed that these DEGs in $\mathrm{CD}^{+} \mathrm{T}$ cells are involved in numerous

412 biological pathways including immune system process, defense response, cell activation,

413 adaptive immune response, cytokine production, regulation of $\mathrm{T}$ cell activation and proliferation,

414 MHC protein complex binding, regulation of programmed cell death, chemokine regulation,

415 autoimmunity, signaling like TNF, NF-kappa B and others which are illustrated in the Manhattan

416 plot. The relevant pathways related to our project were highlighted and ID details are given about

417 each pathway. This information is shown in the table according to the ID of each pathway (Fig.

418 4D). The whole list of differentially expressed functional pathways involved in $\mathrm{CD} 4^{+} \mathrm{T}$ cells are

419 listed in Supplementary Table 2. When we performed GSEA analysis of these genes using the

420 Hallmark pathways collection from Molecular Signatures Database (MSigDB)(27) we observed

421 that TNF- $\alpha$ signaling via NF-k $\beta$ is enriched in WT compared to Cat-Tg in pre-transplanted

422 samples (Sup.Fig.2A). Interestingly, in post-transplant day 7 samples, TNF- $\alpha$ signaling via NF-

$423 \mathrm{k} \beta$, IFN- $\gamma$, IFN- $\alpha$, inflammatory responses, and apoptosis pathways are enriched in $\mathrm{Cat}$ - $\mathrm{Tg}$ rather 424 than WT (Sup.Fig.2B).

425 We also analyzed the $\mathrm{CD}^{+} \mathrm{T}$ cell samples and performed principal component analysis

426 (PCA) of $\mathrm{CD}^{+} \mathrm{T}$ cells. We again identified four groups in which pre-transplanted samples were

427 clearly separated, while post-transplant samples were not separated as well as pre-transplant

428 samples along PC1 (32.2\%) and PC2 (15.3\%) (Fig. 5A). Further analysis of these cell

429 populations identified $~ 250$ differentially expressed genes (DEGs; FDR <0.1) between WT and

430 Cat-Tg (Supplementary Table 3), of which 175 genes were downregulated while 80 genes were 
431 upregulated, and these DEGs are plotted on a volcano plot (Fig. 5B). The use of a Spearman

432 correlation method associated with hierarchical clustering of $\mathrm{CD}^{+} \mathrm{T}$ cell samples showed the

433 same clustering as of $\mathrm{CD}^{+} \mathrm{T}$ cell samples. (Fig. 5C). DEGs between Cat-Tg and WT in CD8 ${ }^{+} \mathrm{T}$

434 cell were averaged by group and gene co-regulation was determined by hierarchical clustering

435 using Pearson correlation with a grouping cutoff $(k)$ of 4 . Each generated module contributed to

436 the different pathway enrichment. Gene expression is averaged by group ( $n \square=\square 3$ ) for clarity and

437 displayed as $z$ score across each row. (Fig. 5C).

438 Functional pathway analysis revealed that the DEGs in $\mathrm{CD}^{+} \mathrm{T}$ cells are involved in

439 similar biological pathways to the DEGs seen in $\mathrm{CD}^{+} \mathrm{T}$ cell, as well as in TCR signaling,

440 hematopoietic cell lineage, Th1, Th2 and Th17 cell differentiation, inflammatory bowel disease,

441 allograft rejection, graft-versus-host-disease, and others which are illustrated in the Manhattan

442 plot. The important pathways related to our project were highlighted and ID details about each

443 pathway are shown in the table. This information is given according to the ID of each pathway

444 (Fig. 5D). The whole list of differentially expressed functional pathways involved in $\mathrm{CD}^{+} \mathrm{T}$

445 cells is listed in Supplementary Table 4. When we performed GSEA analysis of these genes

446 using the Hallmark pathways collection from Molecular Signatures Database (MSigDB)(27), we

447 observed that TNF- $\alpha$ signaling via NF-k $\beta$, KRAS signaling, IFN- $\gamma$ response, inflammatory

448 response, IL6-JAK-STAT3 signaling, IL2-STAT-5 signaling, and allograft rejection pathways

449 are enriched in WT compared to Cat-Tg in pre-transplanted samples (Sup.Fig.3A). Once again,

450 in post-transplant day 7 samples, TNF- $\alpha$ signaling via NF-k $\beta$, KRAS signaling,

451 PI3K/AKT/MTOR signaling, IFN- $\gamma$ and IFN- $\alpha$ response, inflammatory response,

452 IL6/JAK/STAT3 signaling, IL2/STAT-5 signaling, and allograft rejection pathways are enriched

453 in Cat-Tg compared to WT (Sup.Fig.3B). Altogether these data suggest that $\beta$-catenin plays an 
454 important role in regulating the immune response to allo-antigens by controlling gene expression 455 programs in mature and alloactivated $\mathrm{T}$ cells.

456

Wnt/ $\beta$-catenin over-expression specifically affects $\mathrm{CD8}^{+} \mathrm{T}$ cell functions.

458 The pathogenesis of GVHD involves migration of donor T cells into the target organs in the 459 recipient, including liver, small intestine, and skin $(33,34)$. GVHD occurs in a subset of organs 460 and involves early migration of alloreactive $\mathrm{T}$ cells into these organs followed by $\mathrm{T}$ cell 461 expansion and later tissue destruction $(16,35)$. To examine whether over-expression of Wnt/ $\beta$ 462 catenin affects donor T cell migration, irradiated BALB/c recipient mice were injected with $463 \mathrm{CD}^{+} \mathrm{T}$ cells and CD4 ${ }^{+} \mathrm{T}$ cells from Cat-Tg $\left(\mathrm{CD} 45.2^{+}\right)$and WT B6-Ly5.1 $\left(\mathrm{CD} 45.1^{+}\right)$mice 464 mixed at a 1:1 ratio of WT: Cat-Tg (Fig. 6A). A total of $1 \times 10^{6} \mathrm{~T}$ cells were injected, and the 465 cells were checked prior to transplant for a 1:1 ratio of CD4/CD8 for each strain, and for a 1:1 466 ratio of donor strains (Fig. 6A). As a control, we also transplanted WT CD45.2 (C57BL/6) and 467 WT CD45.1 (B6-Ly5.1) cells at 1:1 ratio of WT(CD45.2): WT(CD45.1). Once again 1x106 T 468 cells were injected and cells were checked prior to transplant for a 1:1 ratio of CD4/CD8 for each 469 strain, and for a 1:1 ratio of donor strains (Fig. 6A). At 7 days post transplantation, recipient 470 mice were examined for the presence of donor T cells in the spleen, liver and small intestines.

471 Our data show that recipient mice transplanted with WT CD45.1 and WT CD45.2 had 472 significantly reduced donor $\mathrm{CD}^{+}$cells versus donor $\mathrm{CD}^{+} \mathrm{T}$ cells in the spleen and liver. Next, 473 we examined transplanted $\mathrm{CD}^{+}$and $\mathrm{CD}^{+} \mathrm{T}$ cells by CD45.1 and CD45.2 and we did not 474 observe significant differences among $\mathrm{CD}^{+} \mathrm{T}$ cells in spleen. We observed that donor $\mathrm{CD}^{+} \mathrm{T}$ 475 cells were more skewed toward WT C57BL/6 cell (CD45.2) (Fig. 6B, Sup.Fig.4A). Next, we 476 examine donor T cell migration into liver in recipient mice transplanted with WT CD45.1 or WT 
477 CD45.2 cells. We observed a similar effect on donor T cells migration as we observed in

478 recipient spleen (Fig. 6C, Sup. Fig. 4B). We also examined donor T cell migration into small

479 intestines of recipient mice transplanted with WT CD45.1 or WT CD45.2 cells. We did not

480 observe differences in $\mathrm{CD}^{+}$to $\mathrm{CD}^{+}$donor $\mathrm{T}$ cells ratios, and also, we also did not observe

481 significant differences in CD45.1/CD45.2 expression in $\mathrm{CD}^{+} \mathrm{T}$ cells either from small intestine.

482 We did observe donor CD4 ${ }^{+}$T cells were more skew toward WT C57 cells (CD45.2+) (Sup.

483 Fig4C). When we examined spleens from recipient mice transplanted with CD45.1 WT and

$484 \mathrm{CD} 45.2 \mathrm{Cat}-\mathrm{Tg}$ cells, we observed that the ratio of $\mathrm{CD}^{+}$and $\mathrm{CD} 8^{+} \mathrm{T}$ cell in the spleen was

485 similar to that seen in CD45.1 WT: WT CD45.2 transplanted mice. However, we observed a

486 significant reduction in donor $\mathrm{CD}^{+} \mathrm{T}$ cells from CD45.2 Cat-Tg mice in recipient mouse spleen

487 (Fig. 6D, Sup.Fig.4D). We also observed that there was no significant migration defect on donor

$488 \mathrm{CD}^{+} \mathrm{T}$ cells; however, we observed a significant decrease in $\mathrm{CD}^{+} \mathrm{T}$ cell migration to recipient

489 liver (one of the GVHD target organs) (Fig. 6E, Sup.Fig.4E). We also looked at the donor T cell

490 migration into small intestines (another target organ of GVHD), and found significantly reduced

$491 \mathrm{CD}^{+} \mathrm{T}$ cells compared to $\mathrm{CD}^{+} \mathrm{T}$ cells from donors after transplantation. There was a

492 significant reduction in $\mathrm{CD}^{+}$donor T cells from Cat-Tg (CD45.2) mice in recipient spleen, and

493 we observed that donor $\mathrm{CD}^{+} \mathrm{T}$ cells were more skewed towards Cat-Tg cells (CD45.2)

494 (Sup.Fig.4F). To investigate the underlying mechanism behind these changes, we performed

495 pathway analysis using RNA seq as an unbiased approach. Our data confirmed that both CD4 ${ }^{+}$

496 and $\mathrm{CD}^{+}$T cells are affected by Wnt/ $\beta$-catenin over-expression. We observed that KEGG

497 pathways including cell adhesion molecules (10 genes) were affected in $\mathrm{CD}^{+} \mathrm{T}$ cells from $\mathrm{Cat}$ -

$498 T g$ mice compared to WT mice. Our data show that in $\mathrm{CD}^{+} \mathrm{T}$ cells from $\mathrm{Cat}-\mathrm{Tg}$ mice compared

499 to WT mice, in addition to the KEGG Cell adhesion molecules pathway, we also observed 18 
500 genes regulating cell to cell adhesion pathways (from GO: BP source) that were differentially

501 regulated. We also observed that C-C chemokine receptor activity, cell chemotaxis, and cell

502 migration (specifically $\mathrm{T}$ cell migration genes) were more significantly affected in $\mathrm{CD} 8^{+} \mathrm{T}$ cells

503 (Cat-Tg vs. WT mice) than in $\mathrm{CD}^{+}{ }^{+} \mathrm{T}$ cells. Furthermore, we also observed that genes involved

504 in lymphocyte and $\mathrm{T}$ cell proliferation were more significantly affected in $\mathrm{CD} 8^{+} \mathrm{T}$ cells $(30$

505 genes) than in $\mathrm{CD}^{+} \mathrm{T}$ cells (18 genes) (Fig. 6F).

506 Using histological staining for H\&E, we also observed leukocyte infiltration into GVHD

507 target organs like liver and small intestine (SI)(33) in WT T cell recipients, but not as much in

508 Cat-Tg T cell recipients (Fig. 6G) and (Supp. Fig.5). These data suggest that CD8 ${ }^{+} \mathrm{T}$ cells from

509 Cat- $T g$ mice have significantly been affected by $\beta$-catenin over-expression, and caused less

510 tissue damage to GVHD target tissues. 


\section{Discussion}

513 In this report, we demonstrate that over-expression of $\mathrm{Wnt} / \beta$-catenin regulates allo-reactive $\mathrm{T}$

514 cells for the treatment of hematological malignancies. Both $\mathrm{CD}^{+}$and $\mathrm{CD}^{+} \mathrm{T}$ cells from mice

515 over-expressing $\beta$-catenin (Cat-Tg mice) showed significantly reduced GVHD pathogenesis,

516 while maintaining GVL in models of allo-HSCT. $\mathrm{CD}^{+}$and $\mathrm{CD}^{+}{ }^{+}$T cells from $\mathrm{Cat}-\mathrm{Tg}$ mice

517 expressed higher levels of CD44 and PD-1 markers. CD8 ${ }^{+}$T cells from $\mathrm{Cat}-\mathrm{Tg}$ mice also

518 expressed higher Eomes and CD122. We did not observe any differences in TCF-1, T-bet or

519 CTLA-4 expression. $\mathrm{CD}^{+} \mathrm{T}$ cells from $\mathrm{Cat}-\mathrm{Tg}$ mice showed frequencies of central memory and 520 transitioning cells, but a reduced naïve cell population.

521 Several lines of evidence suggested that CD44 and CD122 $2^{\text {hi }}$ T cells do not induce

522 GVHD(36-38). Our data showed that a high proportion of $\mathrm{CD}^{+} \mathrm{T}$ cells from $\mathrm{Cat}-\mathrm{Tg}$ mice are

$523 \mathrm{CD} 44^{\mathrm{hi}}$ and CD122 $2^{\text {hi }}$ and express higher levels of Eomes (IMP phenotype) (29). Previously, it has

524 been suggested that the IMP phenotype might be due to higher expression of IL-4 in the in the 525 thymus of Cat-Tg mice, which can result in the IMP phenotype (39). However, published data

526 have indicated that the IMP phenotype is not dependent on IL-4 expression specifically in Cat-

$527 T g$ mice $(8,40)$. These findings would indicate that higher Eomes expression and the IMP

528 phenotype in $\mathrm{Cat}$ - $\mathrm{Tg}$ mice due to $\beta$-catenin over-expression allows these cells to have anti-tumor 529 activity in a T cell-intrinsic manner.

$530 \quad$ Several lines of evidence also suggest that $\beta$-catenin plays a central role in $\mathrm{T}$ cell 531 development $(12,41,42)$. Experiments using either loss of $\beta$-catenin or enforced expression of 532 stabilized $\beta$-catenin have further identified a role for $\beta$-catenin at multiple stages of $\mathrm{T}$ cell 533 development $(42,43)$. Adoptive transfer of Wnt-treated $\mathrm{CD}^{+} \mathrm{T}$ cells was shown to enhance 534 anti-tumor activity in vivo (44). Our data provide evidence that $\mathrm{CD}^{+} \mathrm{T}$ cells from $\mathrm{Cat}-\mathrm{Tg}$ mice 
535 express higher levels of granzyme B and perforin, and higher expression of Eomes, and these

536 cells also exhibited enhanced cytotoxicity. Constitutive activation of the TCF- $1 / \beta$-catenin

537 pathway in vivo has been shown to favor generation of memory $\mathrm{CD}^{+} \mathrm{T}$ cells (45).

538 To examine how T cells from Cat- $\mathrm{Tg}$ mice maintain GVL function without GVHD

539 damage, we examined proinflammatory cytokine expression. Our data show that donor T cells

540 from Cat-Tg mice express significantly less proinflammatory cytokines both on a serum level

541 and on a cellular level in our allo-HSCT model. Over-expression of $\beta$-catenin did not alter the

542 signaling molecules ERK, PLC $\gamma 1$, and IRF-4. Wnt/ $\beta$-catenin signaling, a highly conserved

543 pathway through evolution, regulates key cellular functions including proliferation,

544 differentiation, migration, genetic stability, apoptosis, and stem cell renewal $(43,45)$. Donor T

545 cells were examined for proliferation using an EdU incorporation assay. Both donor $\mathrm{CD}^{+}$and

$546 \mathrm{CD}^{+} \mathrm{T}$ cells from $\mathrm{Cat}-\mathrm{Tg}$ mice showed a trend toward reduced proliferation compared to donor

547 T cells from WT mice. To investigate how the Wnt/ $\beta$-catenin over-expression affects $\mathrm{T}$ cell gene

548 expression, we utilized an unbiased RNA sequencing approach. Transcriptome analysis by RNA

549 sequencing revealed that there were 150 differentially expressed genes in $\mathrm{CD} 4^{+} \mathrm{T}$ cells

550 (Sup.Table 1), and over 250 genes affected by over-expression of $\beta$-catenin in $\mathrm{CD}^{+} \mathrm{T}$ cells

551 (Sup.Table 3). Pathway analysis revealed that the differentially expressed genes in CD ${ }^{+} \mathrm{T}$ cells

552 are involved in regulation of immune system processes, $\mathrm{T}$ cell and B cell activation, $\mathrm{T}$ cell

553 proliferation, adaptive immune responses, immune system development, inflammatory

554 responses, cytokine production, signaling, cell adhesion, and chemokine receptors. Genes that

555 were differentially expressed in $\mathrm{CD}^{+} \mathrm{T}$ cells were involved in similar pathways, along with

556 hematopoietic cell lineage, GVHD, allograft rejection, Th1, Th2, Th17 differentiation, and other

557 pathways. Therefore, $\beta$-catenin plays a critical role in regulating gene expression programs of 
mature $\mathrm{T}$ cells during alloactivation. Taken together, these data suggest that $\mathrm{Wnt} / \beta$-catenin could represent a potential target for the separation of GVHD and GVL responses after allo-HSCT.

560 Next, we sought to investigate how these transcriptome changes affected donor T cell function in 561 the development of GVHD pathophysiology. Donor T cell proliferation and migration to GVHD 562 target organs are considered hallmarks of GVHD (4). Therefore, we examined whether T cells 563 from $C a t-T g$ are defective in migration to GVHD target organs. We observed that only $\mathrm{CD}^{+} \mathrm{T}$ 564 cells from Cat-Tg mice are likely to be defective. This effect could also be due to the observed 565 decreased in proliferation or decreased cell survival, but alteration on gene programs related to 566 migration suggested that Cat-Tg CD8+T cells are at least partly migration defective. When 567 transplanting a 1:1 ratio of WT: $\mathrm{Cat}-\mathrm{Tg} \mathrm{T}$ cells, we did not observe any differences in migration 568 of $\mathrm{CD}^{+} \mathrm{T}$ cells from $\mathrm{Cat}-\mathrm{Tg}$ mice compared to WT mice in spleen and liver. We observed a 569 significant reduction in $\mathrm{CD}^{+} \mathrm{T}$ cells from $\mathrm{Cat}-\mathrm{Tg}$ mice in spleen. Similarly, we observed a 570 significant reduction in $\mathrm{CD}^{+} \mathrm{T}$ cells from $\mathrm{Cat}-\mathrm{Tg}$ mice in liver and small intestines as well. We 571 observed that donor T cells from $\mathrm{Cat}$-Tg mice trend towards decreased proliferation. We also 572 examined genes involved in total lymphocyte proliferation and specifically genes involved in $\mathrm{T}$ 573 cell proliferation, which were affected in both $\mathrm{CD}^{+}$and $\mathrm{CD} 8^{+} \mathrm{T}$ cells, but significantly more 574 genes were affected in donor $\mathrm{CD}^{+} \mathrm{T}$ cells compared to $\mathrm{CD} 4^{+} \mathrm{T}$ cells from $\mathrm{Cat}-\mathrm{Tg}$ mice. Activation-induced cell death (AICD) of lymphocytes is an apoptotic pathway that might be involved in the control of $\mathrm{CD}^{+} \mathrm{T}$ cell homeostasis in Cat-Tg mice (46). Therefore, we

577 performed pathway analysis, and our data confirm that many pathways were significantly 578 affected in both $\mathrm{CD}^{+}$and $\mathrm{CD}^{+} \mathrm{T}$ cells from Cat-Tg mice. Our data confirmed that cell adhesion 579 molecules were more significantly affected in $\mathrm{CD}^{+}{ }^{\mathrm{T}}$ cells than in $\mathrm{CD}^{+} \mathrm{T}$ cell from $\mathrm{Cat}-\mathrm{Tg}$ 580 mice. We also observed a significant reduction in cell adhesion molecule expression (13 genes) 
581 cell adhesion molecule expression (18 genes) in CD8. Published data have shown that irradiation

582 causes the upregulation of cell adhesion molecules and provides early costimulatory signals to

583 incoming donor $\mathrm{T}$ cells in the intestine, followed by a cascade of proinflammatory signals in

584 other organs once the alloresponse is established (47). Our data provide evidence that both CD4

585 and $\mathrm{CD}^{+} \mathrm{T}$ cells from $\mathrm{Cat}-\mathrm{Tg}$ mice show significant reductions in adhesion molecules, but $\mathrm{CD} 8^{+}$

586 T cells from Cat-Tg mice were more significantly affected.

587 We also examined pathways involved in lymphocyte migration by pathway analysis. We

588 observed that genes involved in chemokine receptor activity, C-C chemokine binding, CCR1

589 chemokine receptor binding, CCR5 chemokine receptor binding, and several genes involved in

590 the regulation of lymphocyte migration were affected in $\mathrm{CD}^{+}{ }^{+} \mathrm{T}$ cells. More genes in similar

591 pathways like C-C chemokine receptor activity, Cell chemotaxis, Chemokine receptors binding

592 chemokines, and especially Cell migration and T cell migration were found to be significantly

593 altered in $\mathrm{CD}^{+} \mathrm{T}$ cells from Cat-Tg mice compared to WT mice. Inflammatory chemokines are

594 expressed in inflamed tissues by both hematopoetic and non-hematopoetic cells upon stimulation

595 by pro-inflammatory cytokines, including $\mathrm{TNF} \alpha$ and IFN- $\gamma$ (48). Inflammatory chemokines of

596 the $\mathrm{CC}, \mathrm{C}$, or $\mathrm{CXC} 3 \mathrm{C}$ families are also increasingly expressed after allogeneic transplantation

597 (48). Cellular sources of chemokines may differ between specific target organs, and contribute

598 considerably to the severity of GVHD. Our data show that inflammatory chemokines are

599 significantly affected in T cells from Cat- $\mathrm{Tg}$ mice, which contributed to less severe GVHD

600 development. Our model demonstrated that $\mathrm{T}$ cells from Cat-Tg mice significantly reduce the

601 development of acute GVHD.

602 Recently, several lines of evidence have suggested that modulating intracellular signaling 603 pathways that regulate $\mathrm{T}$ cell responses and survival can be used to inhibit $\mathrm{T}$ cell alloresponses, $\mathrm{T}$ 
604 cell survival, and thus, GVHD (49). This has included targeting the transcription factor nuclear

605 factor kappa B (NFkB). As NFkB has long been known to play a critical role in T cell biology,

606 particularly with respect to cytokine responses, it has always been an attractive target (50).

607 However, targeting of NFkB has been hampered by a lack of reagents that have favorable

608 pharmacokinetics, resulting in systemic NFkB inhibition without toxicity $(51,52)$. Our data show

609 that $\mathrm{T}$ cells (both $\mathrm{CD} 4$ and $\mathrm{CD} 8^{+}$) from $\mathrm{Cat}-\mathrm{Tg}$ mice have significant changes to the NFkB

610 pathways.

$611 \mathrm{NF \kappa B}$ is a transcription factor that controls the expression of a number of genes important

612 for mediating immune and inflammatory responses. Several lines of evidence have recently

613 suggested that inhibiting NFkB signaling ameliorates GVHD in both mice and humans (53).

614 Bortezomib and PS-1145 are small molecule inhibitors that have been used to treat acute GVHD

615 (54). In our RNAseq results, we also observed a number of B cell activation and regulation

616 pathways, as well as immunoglobulin regulation pathways, which were significantly affected by

$617 \beta$-catenin over-expression in both CD4 and CD8+ T cells. Even though we didn't investigate

618 how over-expression of $\beta$-catenin impacts B cells in GVHD pathogenesis at a functional level, it

619 has been previously shown that B cells play an important role in pathogenesis of GVHD(55), so

620 this could be another reason why over-expression of $\beta$-catenin caused less GVHD.

621 The use of agonists to activate $\mathrm{Wnt} / \beta$-catenin signaling will have considerable clinical

622 implications for the improvement of immunotherapies based on ex vivo manipulation of $\mathrm{T}$

623 lymphocytes for adoptive transplantation. Several mouse models have shown that blocking Gsk-

$6243 \beta$ using small molecule inhibitors resulted in the generation of stem-like memory $\mathrm{CD}^{+} \mathrm{T}$ cells,

625 which have the potential to be highly effective in immunotherapy (56). Using pharmacological

626 approaches, human $\mathrm{CD}^{+} \mathrm{T}$ cells with stem-like properties can be generated using antagonists of 
627 Wnt signaling, and can be genetically engineered to have tumor-specific properties (57). For the

628 first time we showed that $\mathrm{Wnt} / \beta$-catenin is not only critical for T cell development, but also plays

629 a significant role in T cells-mediated GVHD after allogeneic transplantation. Our functional and

630 genetic data demonstrated that the $\mathrm{Wnt} / \beta$-catenin pathways play a central role in uncoupling

631 GVHD from GVL functions. 
632 Acknowledgements: We thank all members of the Karimi laboratory for helpful discussions.

633 This research was funded in part by a grant from the National Blood Foundation Scholar Award

634 to (MK), the National Institutes of Health (NIH LRP \#L6 MD0010106 and K22 (AI130182) to

$635 \mathrm{MK})$, and an Upstate Medical University Cancer grant (1146249-1-75632) to MK. JMS and AV

636 are supported by the Intramural Research Program of the National Institute of Aging.

637

638

639 Author contributions: MM, RH, SM, AM, RD, and MK performed experiments; JMS provided

640 valuable reagents; and helped edit the manuscript. AV, provided reagents. AW helped with RNA

641 sequencing analysis. MM, RH, and MK designed experiments, analyzed the data, and wrote the 642 manuscript.

643

644 Conflict of Interest: The authors declare no conflicts of interest.

645

646

647

648

649

650

651

652 


\section{Figure Legends}

654 Figure 1. Wnt/ $\beta$-catenin over-expression retains the GVL effect but avoids GVHD

655 during allo-HSCT. 1 X $10^{6}$ purified WT or Cat-Tg CD3+ T cells were transplanted into

656 lethally irradiated $\mathrm{BALB} / \mathrm{c}$ recipient mice along, with $10 \mathrm{X} 10^{6} \mathrm{~T}$ cell depleted bone marrow

657 cells from WT mice and $1 \times 10^{5}$ B-ALL-luc cells. Host BALB/c mice were imaged using the

658 IVIS50 system 3 times a week. Group 1 received T cell-depleted bone marrow only (labeled 659 as $\left.{ }_{\mathrm{TCD}} \mathrm{BM}\right)$. Group 2 received $10 \mathrm{X} 10^{6}{ }_{\mathrm{TCD}} \mathrm{BM}$ from WT mice and $1 \mathrm{X} 10^{5} \mathrm{~B}-\mathrm{ALL}-\mathrm{luc}$ cells $660\left(_{\mathrm{TCD}} \mathrm{BM}+\mathrm{B}-\mathrm{ALL}^{l u c+}\right)$. Group 3 was transplanted with $10 \times 10^{6}{ }_{\mathrm{TCD}} \mathrm{BM}$ from WT mice and $6611 \times 10^{6}$ purified WT $\mathrm{CD}^{+} \mathrm{T}$ cells, along with $1 \times 10^{5} \mathrm{~B}-\mathrm{ALL}^{\text {luct }}$ cells $\left(\mathrm{TCD} \mathrm{BM}+\mathrm{B}-\mathrm{ALL}^{\text {luct }}\right.$

662 WT). Group 4 received $10 \times 10^{6}{ }_{\mathrm{TCD}} \mathrm{BM}$ from WT mice and $1 \mathrm{X} 10^{6}$ purified $\mathrm{Cat}-\mathrm{Tg} \mathrm{CD}^{+}{ }^{\mathrm{T}}$

663 cells, along with $1 \times 10^{5} \mathrm{~B}-\mathrm{ALL}-l u c+$ cells $\left(\mathrm{TCD}_{\mathrm{BC}} \mathrm{M}+\mathrm{B}-\mathrm{ALL}{ }^{l u c}+C a t-T g\right)$. (A) Recipient

664 BALB/c mice were imaged using IVIS50 3 times a week. The mice were also monitored for

665 (B) survival, (C) changes in body weight, and (D) clinical score for 65 days post BMT. (E)

666 Quantitated luciferase bioluminescence of tumor growth. Statistical analysis for survival and 667 clinical score was performed using log-rank test and one-way ANOVA, respectively. For 668 weight changes and clinical score, one representative of 2 independent experiments is shown 669 ( $\mathrm{n}=3$ mice/group for BM alone; $\mathrm{n}=5$ experimental mice/group for all three other groups)

670 Survival is a combination of 2 experiments. Note: Control mouse is a naïve mouse used as a 671 negative control for BLI.

673 Figure 2. T cells from Cat-Tg mice exhibit enhanced T cell IMP phenotypes and enhanced

674 GVL cytotoxicity. (A-B) Purified CD3 ${ }^{+} \mathrm{T}$ cells from WT and $\mathrm{Cat}-\mathrm{Tg} \mathrm{T}$ cells were examined for 675 expression of CD44, CD122, Eomes, T-bet, PD-1, CTLA-4 and TCF-1 by flow cytometry. These 
676

677

678

679

680

681

682

683

684

685

686

687

688

689

690

691

692

693

694

695

696

697

698

markers were examined for both $(\mathbf{A}) \mathrm{CD}^{+}$and $(\mathbf{B}) \mathrm{CD}^{+} \mathrm{T}$ cells. (C-D) Quantification of 3 different experiments of CD44, CD122, Eomes, T-bet, PD-1, CTLA-4 and TCF-1 in (C) CD8 ${ }^{+}$

or in (D) $\mathrm{CD}^{+}$. (E) $\mathrm{CD}^{+}(\mathbf{F}) \mathrm{CD}^{+} \mathrm{T}$ cells from WT and $\mathrm{Cat}-\mathrm{Tg}$ mice were examined for effector memory, central memory, transitioning to activation (TA), and naïve population frequencies. (G) Purified T cells were examined for expression of perforin, granzyme B, and $\beta$ actin by western blot. (H-I) Quantitative analysis of perforin (H) and granzyme B (I) expression from western blot data, normalized against $\beta$-Actin. (J) Ex vivo purified T cells were used in a cytotoxicity assay against primary tumor target B-ALLluc+ cells at a 40:1, 20:1, or 10:1 effector to target ratio. Statistical analysis was performed using two-way ANOVA, one-way ANOVA confirmed by Student's $t$-test, p-values are presented. Symbol meanings for P-values are: ns - P > $0.05 ; *-\mathrm{P} \leq 0.05 ; * *-\mathrm{P} \leq 0.01 ; * * *-\mathrm{P} \leq 0.001 ; * * * *-\mathrm{P} \leq 0.0001(\mathrm{n}=3$ mice per group $)$

\section{Figure 3. Over-expression of $\beta$-Catenin reduces $\mathbf{T}$ cell inflammatory cytokine production}

\section{and proliferation without affecting signaling molecules. (A) $1 \times 10^{6}$ purified WT or $C a t-T g$}

$\mathrm{CD}^{+} \mathrm{T}$ cells were transplanted with ${ }_{\mathrm{TCD}} \mathrm{BM}$ into irradiated $\mathrm{BALB} / \mathrm{c}$ mice. At day 7 post allo-

HSCT, recipient BALB/c were euthanized and serum cytokines (IFN- $\gamma$, TNF- $\alpha$, IL-2, IL-5, IL-6, IL-4, IL-10, IL-9, IL17A, IL-17F, IL-22, and IL-13) were determined by multiplex ELISA. (BC) Intracellular IFN- $\gamma$ and TNF- $\alpha$ expression by donor CD4 (B) and CD8 (C) T cells after 6 hr stimulation with anti-CD3/anti-CD28 and GolgiPlug, as determined by flow cytometry. (D-E) Quantified IFN- $\gamma$ and TNF- $\alpha$ expression for (B-C). (F-H) Ex vivo proliferation of donor CD4 ${ }^{+}$or $\mathrm{CD}^{+} \mathrm{T}$ cells from Cat-Tg or WT mice. Lethally irradiated recipient BALB/c mice were transplanted as mentioned above, with either WT or Cat-Tg donor $\mathrm{CD}^{+} \mathrm{T}$ cells. Recipient mice were given EdU in PBS i.p. (25 mg/kg in $100 \mu \mathrm{l})$ for last 2 days. At 7 days post- 
699 allotransplantation, recipient mice were sacrificed and examined for proliferation by EdU

700 incorporation via flow cytometry. (I) Purified $\mathrm{CD}^{+}{ }^{\mathrm{WT}}$ and $\mathrm{Cat}-\mathrm{Tg} \mathrm{T}$ cells were examined for

701 expression of ERK, PLC $\gamma$-1, and IRF-4 by western blot. (J) Quantitative analysis from western

702 blots in (I), using ImageLab software to normalize to $\beta$-Actin. Symbol meanings for P values

703 are: $\mathrm{ns}-\mathrm{P}>0.05 ; *-\mathrm{P} \leq 0.05 ; * *-\mathrm{P} \leq 0.01 ; * * *-\mathrm{P} \leq 0.001 ; * * * *-\mathrm{P} \leq 0.0001$. (For Fig 3A-G,

$704 \mathrm{n}=5$ mice per group, for Fig $3 \mathrm{H}-\mathrm{I}, \mathrm{n}=3$ mice used per group)

705

706 Figure 4. $\beta$-catenin over-expression differentially regulates gene expression in $\mathrm{CD4}^{+} \mathbf{T}$ cells 707 during GVHD.

708 (A) PCA analysis showing clustering of pre-transplanted and post-transplanted day $7 \mathrm{CD}^{+} \mathrm{T}$

709 cells by strain and by timepoint. Samples grouped for strain by color and for timepoint by shape.

710 All replicates are shown $(\mathrm{n}=3)$. (B) Volcano plot displaying differentially expressed genes

711 (FDR $<0.1)$ between $\mathrm{Cat}-\mathrm{Tg}$ and WT day $7 \mathrm{CD}^{+} \mathrm{T}$ cell samples. Genes up-regulated (red) and

712 down-regulated (blue) are labeled. (C) Hierarchical clustering and heat map illustrating

713 expression of genes compared between different groups selected by strain and timepoint. All

714 replicates are shown $(n=3)$ for each group. (D) Manhattan plot showing functional pathway

715 analysis of $\mathrm{CD} 4^{+} \mathrm{T}$ cells. Using the online tool gProfiler and the ordered g:GOSt query, we

716 assessed which biological processes (BP) were linked to the list of 150 significantly

717 differentially expressed genes from $\mathrm{CD}^{+} \mathrm{T}$ cells. The $\mathrm{x}$-axis represents functional terms that are

718 grouped and color-coded by data sources [molecular function (MF), biological process (BP), cell

719 component (CC)]. The y-axis shows the adjusted enrichment $p$-values on a negative log 10 scale.

720 Adjusted p-values g:GOSt used Bonferroni correction and a threshold of 0.1. On the table, 
721 adjusted p-values were color coded as yellow for insignificant findings to dark blue with highest

722 significance. $(\mathrm{n}=3$ mice per group)

723

724 Figure 5. $\beta$-catenin over-expression differentially regulates gene expression in $\mathrm{CDB}^{+} \mathbf{T}$ cells 725 during GVHD.

726 (A) PCA analysis showing clustering of pre-transplanted and post-transplanted day $7 \mathrm{CD}^{+} \mathrm{T}$

727 cells by strain and by timepoint. Samples grouped for strain by color and for timepoint by shape.

728 All replicates are shown $(\mathrm{n}=3)$. (B) Volcano plot displaying differentially expressed genes

729 (FDR $<0.1)$ between $C a t-T g$ and WT day $7 \mathrm{CD}^{+} \mathrm{T}$ cell samples. Genes up-regulated (red) and

730 down-regulated (blue) are labeled. (C) Hierarchical clustering and heat map illustrating

731 expression of genes compared between different groups selected by strain and timepoint. All

732 replicates are shown $(\mathrm{n}=3)$ for each group. (D) Manhattan plot showing functional pathway

733 analysis of $\mathrm{CD}^{+} \mathrm{T}$ cells. Using the online tool gProfiler and the ordered g:GOSt query, we

734 assessed which biological processes (BP) were linked to the list of 150 significantly

735 differentially expressed genes from $\mathrm{CD}^{+} \mathrm{T}$ cells. The $\mathrm{x}$-axis represents functional terms that are

736 grouped and color-coded by data sources [molecular function (MF), biological process (BP), cell

737 component (CC)]. The y-axis shows the adjusted enrichment p-values on a negative $\log 10$ scale.

738 Adjusted p-values g:GOSt used Bonferroni correction and a threshold of 0.1. On the table,

739 adjusted p-values were color coded as yellow for insignificant findings to dark blue with highest

740 significance. $(\mathrm{n}=3$ mice per group)

741

742 Figure 6. Wnt/ $\beta$-catenin over expression specifically affects $\mathrm{CD8}^{+} \mathbf{T}$ cell functions. (A)

743 Irradiated BALB/c mice were allo-transplanted and injected with MACS-sorted WT and Cat-Tg 
$744 \mathrm{CD}^{+}$or $\mathrm{CD}^{+} \mathrm{T}$ cells mixed at a 1:1 ratio. Flow analysis of MACS sorted pre-transplanted T

745 cells, showing an approximate 1:1 ratio of CD4:CD8 per strain, and an approximate 1:1 ratio of

746 WT(CD45.1): Cat-Tg (CD45.2): cells (or WT(CD45.1): WT(CD45.2) as control). (B) At day 7

747 post-BMT, the spleen was examined for donor WT(CD45.1): WT(CD45.2) T cells. The

748 percentage of $\mathrm{WT}(\mathrm{CD} 45.1)$ : WT(CD45.2) $\mathrm{CD}^{+}$and $\mathrm{CD}^{+} \mathrm{T}$ cells is shown, as well as the

749 percentage of each donor cell type in spleen. (C) At day 7 post-BMT, the liver was examined for

750 donor T cells. The percentage of WT(CD45.1): WT(CD45.2) $\mathrm{CD}^{+}$and $\mathrm{CD} 8^{+} \mathrm{T}$ cells is shown,

751 as well as the percentage of each donor cell type in liver. (D) At day 7 post-BMT, the spleen was

752 examined for donor WT(CD45.1): Cat-Tg (CD45.2) T cells. The percentage of WT(CD45.1):

753 Cat-Tg (CD45.2) $\mathrm{CD}^{+}$and $\mathrm{CD}^{+}{ }^{\mathrm{T}}$ cells is shown, as well as the percentage of each donor cell

754 type in spleen. (E) At day 7 post-BMT, the liver was examined for donor WT(CD45.1): Cat-Tg

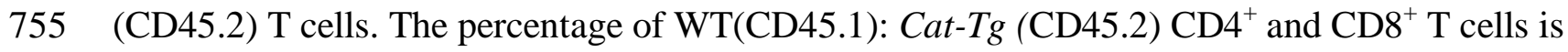

756 shown, as well as the percentage of each donor cell type in liver. (F). Pathways involved in

757 chemokine receptor activity, chemotaxis, migration, and proliferation from functional pathway

758 analysis of $\mathrm{CD}^{+} \mathrm{T}$ cells (Fig. 4D) and $\mathrm{CD}^{+} \mathrm{T}$ cells (Fig 5D). Table compares adjusted $\mathrm{p}$ values

759 and number of genes involved in each pathway between $\mathrm{CD} 4^{+}$and $\mathrm{CD}^{+} \mathrm{T}$ cells. (G) At day 7

760 post-allo-HSCT, small intestines and liver were examined by H\&E staining for tissue damage.

761 Arrows show lymphocyte infiltration and tissue damage. Statistical analysis was performed using

762 one-way ANOVA. Mann Whitney U test, P value presented with the figure. Symbol meaning for

$763 \mathrm{P}$ values are: $\mathrm{ns}-\mathrm{P}>0.05 ; *-\mathrm{P} \leq 0.05 ; * *-\mathrm{P} \leq 0.01$; *** $-\mathrm{P} \leq 0.001$; **** $-\mathrm{P} \leq 0.0001$. (For

764 Fig.6A-E, $n=5$ mice per group, repeated twice, one representative is shown. For Fig.6F-G, n=5

765 mice used per group) 


\section{Supplementary Figure Legends}

\section{Supplementary Figure 1. T cells from Cat-Tg mice exhibit enhanced T cell IMP}

768 phenotypes, related to Figure 2. (A-B) Quantitative analysis of T cells from WT and Cat-Tg

769 mice that were examined for effector memory, central memory, transitioning/activating , and

770 naïve population frequencies. CD4 (A) and CD8 (B) T cells were examined for these populations

771 by flow cytometry. Statistical analysis was performed using two-way ANOVA, one-way

772 ANOVA confirmed by Student's $t$-test, p-values are presented. Symbol meanings for P-values

773 are: $\mathrm{ns}-\mathrm{P}>0.05 ; *-\mathrm{P} \leq 0.05 ; * *-\mathrm{P} \leq 0.01 ; * * *-\mathrm{P} \leq 0.001 ; * * *-\mathrm{P} \leq 0.0001(\mathrm{n}=3$ mice per

774 group)

775

776 Supplementary Figure 2. GSEA enrichment analysis for $\mathrm{CD4}^{+} \mathbf{T}$ cells, related to Figure 4.

777 (A) A bubble chart showing up- or downregulated pathways based on enrichment scores in

778 GSEA in pre-transplanted WT or Cat-Tg $\mathrm{CD}^{+} \mathrm{T}$ cell samples. (B) A bubble chart showing up-

779 or down regulated pathways based on enrichment scores in GSEA in day 7 post-transplant WT

780 or $\mathrm{Cat}-\mathrm{Tg} \mathrm{CD}^{+} \mathrm{T}$ cell samples.

781

782 Supplementary Figure 3. GSEA enrichment analysis for $\mathbf{C D 8}^{+} \mathbf{T}$ cells, related to Figure 5.

783 (A) A bubble chart showing up- or downregulated pathways based on enrichment scores in

784 GSEA in pre-transplanted WT or Cat-Tg CD8 ${ }^{+} \mathrm{T}$ cell samples. (B) A bubble chart showing up-

785 or down regulated pathways based on enrichment scores in GSEA in day 7 post-transplant WT

786 or $\mathrm{Cat}-\mathrm{Tg} \mathrm{CD}^{+} \mathrm{T}$ cell.

787

788 
789 Supplementary Figure 4. Wnt/ $\beta$-catenin over-expression specifically affects $\mathbf{C D 8}^{+} \mathbf{T}^{\text {cell }}$

\section{0 functions, related to Figure 6.}

791 (A-C) Quantitative analysis using flow cytometry of donor $\mathrm{CD}^{+}$and $\mathrm{CD}^{+}{ }^{\mathrm{T}}$ cells isolated from 792 recipient's spleen, liver, and small intestine (SM) seven days post transplantation. Donor CD4 ${ }^{+}$ 793 and $\mathrm{CD}^{+}$T cells were further analyzed by CD45.1 (WT- B6-Ly5.1) and CD45.2 (WT control794 C57BL/6) to identify donor strains. (D-F) Quantitative analysis using flow cytometry of donor $795 \mathrm{CD}^{+}$and $\mathrm{CD}^{+} \mathrm{T}$ cells isolated from recipient spleen, liver, and small intestine (SM) seven days 796 post transplantation. Donor $\mathrm{CD}^{+}$and $\mathrm{CD} 8^{+} \mathrm{T}$ cells were further analyzed by CD45.1 (WT) and

797 CD45.2 (Cat-Tg) to identify donor strains. For statistical analysis we used one-way ANOVA and 798 student's $t$ test, $p$ values are presented. Symbol meaning for $\mathrm{P}$ values are: $\mathrm{ns}-\mathrm{P}>0.05 ; *-\mathrm{P} \leq$ $7990.05 ; * *-\mathrm{P} \leq 0.01 ; * * *-\mathrm{P} \leq 0.001 ; * * * *-\mathrm{P} \leq 0.0001(\mathrm{n}=5$ mice per group, repeated twice, one 800 representative is shown).

801

802

803 Supplementary Figure 5. Quantified scores for GVHD target organ damage, related to 804 Figure 6

805 Tissues obtained from recipient mice were graded for GVHD. Quantified GVHD scores for 806 different groups are shown, with median indicated.. Statistical analysis was performed using 807 Mann Whitney U test.

808

809 
1. Bleakley M, Turtle CJ, and Riddell SR. Augmentation of anti-tumor immunity by adoptive T-cell transfer after allogeneic hematopoietic stem cell transplantation. Expert Rev Hematol. 2012;5(4):409-25.

2. Breems DA, and Lowenberg B. Autologous stem cell transplantation in the treatment of adults with acute myeloid leukaemia. Br J Haematol. 2005;130(6):825-33.

3. Ghimire S, Weber D, Mavin E, Wang XN, Dickinson AM, and Holler E. Pathophysiology of GvHD and Other HSCT-Related Major Complications. Front Immunol. 2017;8:79.

4. Zeiser R. Introduction to a review series on pathophysiology and treatment of acute GVHD. Blood. 2020;136(4):375-6.

5. Li X, Xiang Y, Li F, Yin C, Li B, and Ke X. WNT/beta-Catenin Signaling Pathway Regulating $\mathrm{T}$ Cell-Inflammation in the Tumor Microenvironment. Front Immunol. 2019;10:2293.

6. Haseeb M, Pirzada RH, Ain QU, and Choi S. Wnt Signaling in the Regulation of Immune Cell and Cancer Therapeutics. Cells. 2019;8(11).

7. Driessens G, Zheng Y, Locke F, Cannon JL, Gounari F, and Gajewski TF. Beta-catenin inhibits $\mathrm{T}$ cell activation by selective interference with linker for activation of $\mathrm{T}$ cellsphospholipase C-gamma1 phosphorylation. J Immunol. 2011;186(2):784-90.

8. Yu Q, Sharma A, and Sen JM. TCF1 and beta-catenin regulate T cell development and function. Immunol Res. 2010;47(1-3):45-55.

9. Willinger T, Freeman T, Herbert M, Hasegawa H, McMichael AJ, and Callan MF. Human naive CD8 T cells down-regulate expression of the WNT pathway transcription factors lymphoid enhancer binding factor 1 and transcription factor 7 (T cell factor-1) following antigen encounter in vitro and in vivo. J Immunol. 2006;176(3):1439-46.

10. Ma B, and Hottiger MO. Crosstalk between Wnt/beta-Catenin and NF-kappaB Signaling Pathway during Inflammation. Front Immunol. 2016;7:378.

11. Gattinoni L, Ji Y, and Restifo NP. Wnt/beta-catenin signaling in T-cell immunity and cancer immunotherapy. Clin Cancer Res. 2010;16(19):4695-701.

12. van Loosdregt J, and Coffer PJ. The Role of WNT Signaling in Mature T Cells: T Cell Factor Is Coming Home. J Immunol. 2018;201(8):2193-200.

13. Boudousquie C, Danilo M, Pousse L, Jeevan-Raj B, Angelov GS, Chennupati V, et al. Differences in the transduction of canonical Wnt signals demarcate effector and memory CD8 T cells with distinct recall proliferation capacity. J Immunol. 2014;193(6):2784-91.

14. Cheng Y, Chikwava K, Wu C, Zhang H, Bhagat A, Pei D, et al. LNK/SH2B3 regulates IL-7 receptor signaling in normal and malignant B-progenitors. J Clin Invest. 2016;126(4):1267-81.

15. Mammadli M, Huang W, Harris R, Sultana A, Cheng Y, Tong W, et al. Targeting Interleukin-2-Inducible T-Cell Kinase (ITK) Differentiates GVL and GVHD in AlloHSCT. Front Immunol. 2020;11:593863.

16. Socie G, and Blazar BR. Acute graft-versus-host disease: from the bench to the bedside. Blood. 2009;114(20):4327-36. 
854 17. Perez-Simon JA, Sanchez-Abarca I, Diez-Campelo M, Caballero D, and San Miguel J.

855

856

857

858

859

860

861

862

863

864

865

866

867

868

869

870

871

872

873

874

875

876

877

878

879

880

881

882

883

884

885

886

887

888

889

890

891

892

893

894

895

896

897

898

Chronic graft-versus-host disease: Pathogenesis and clinical management. Drugs. 2006;66(8):1041-57.

18. $\mathrm{Yu} \mathrm{Q}, \mathrm{Xu} \mathrm{M}$, and Sen JM. Beta-catenin expression enhances IL-7 receptor signaling in thymocytes during positive selection. J Immunol. 2007;179(1):126-31.

19. Contag $\mathrm{CH}$, and Bachmann $\mathrm{MH}$. Advances in in vivo bioluminescence imaging of gene expression. Annual review of biomedical engineering. 2002;4:235-60.

20. Cooke KR, Kobzik L, Martin TR, Brewer J, Delmonte J, Jr., Crawford JM, et al. An experimental model of idiopathic pneumonia syndrome after bone marrow transplantation: I. The roles of minor H antigens and endotoxin. Blood. 1996;88(8):32309.

21. Mammadli M, Huang W, Harris R, Xiong H, Weeks S, May A, et al. Targeting SLP76:ITK interaction separates GVHD from GVL in allo-HSCT. iScience. 2021;24(4):102286.

22. Mancusi A, Piccinelli S, Velardi A, and Pierini A. The Effect of TNF-alpha on Regulatory T Cell Function in Graft-versus-Host Disease. Front Immunol. 2018;9:356.

23. Karimi MA, Lee E, Bachmann MH, Salicioni AM, Behrens EM, Kambayashi T, et al. Measuring cytotoxicity by bioluminescence imaging outperforms the standard chromium51 release assay. PLoS One. 2014;9(2):e89357.

24. Law CW, Chen Y, Shi W, and Smyth GK. voom: Precision weights unlock linear model analysis tools for RNA-seq read counts. Genome Biol. 2014;15(2):R29.

25. Greene AE, Charney J, Nichols WW, and Coriell LL. Species identity of insect cell lines. In Vitro. 1972;7(5):313-22.

26. Reimand J, Kull M, Peterson H, Hansen J, and Vilo J. g:Profiler--a web-based toolset for functional profiling of gene lists from large-scale experiments. Nucleic Acids Res. 2007;35(Web Server issue):W193-200.

27. Subramanian A, Tamayo P, Mootha VK, Mukherjee S, Ebert BL, Gillette MA, et al. Gene set enrichment analysis: a knowledge-based approach for interpreting genome-wide expression profiles. Proc Natl Acad Sci U S A. 2005;102(43):15545-50.

28. Harris R, Mammadli M, May A, Yang Q, Fung ITH, Sen JM, et al. TCF-1 in CD4 T cells regulates GVHD severity and persistence. bioRxiv. 2021:2021.03.22.436492.

29. Huang $\mathrm{W}, \mathrm{Hu} \mathrm{J}$, and August A. Cutting edge: innate memory CD8+ T cells are distinct from homeostatic expanded CD8+ $\mathrm{T}$ cells and rapidly respond to primary antigenic stimuli. J Immunol. 2013;190(6):2490-4.

30. Henden AS, and Hill GR. Cytokines in Graft-versus-Host Disease. J Immunol. 2015;194(10):4604-12.

31. Holler E. Cytokines, viruses, and graft-versus-host disease. Curr Opin Hematol. 2002;9(6):479-84.

32. Ju XP, Xu B, Xiao ZP, Li JY, Chen L, Lu SQ, et al. Cytokine expression during acute graft-versus-host disease after allogeneic peripheral stem cell transplantation. Bone Marrow Transplant. 2005;35(12):1179-86.

33. Wysocki CA, Panoskaltsis-Mortari A, Blazar BR, and Serody JS. Leukocyte migration and graft-versus-host disease. Blood. 2005;105(11):4191-9.

34. Gooptu M, and Koreth J. Translational and clinical advances in acute graft-versus-host disease. Haematologica. 2020;105(11):2550-60. 
899 35. Ferrara JL, Cooke KR, Pan L, and Krenger W. The immunopathophysiology of acute

900

901

902

903

904

905

906

907

908

909

910

911

912

913

914

915

916

917

918

919

920

921

922

923

924

925

926

927

928

929

930

931

932

933

934

935

936

937

938

939

940

941

942

943

944

graft-versus-host-disease. Stem Cells. 1996;14(5):473-89.

36. Dutt S, Baker J, Kohrt HE, Kambham N, Sanyal M, Negrin RS, et al. CD8+CD44(hi) but not CD4+CD44(hi) memory $\mathrm{T}$ cells mediate potent graft antilymphoma activity without GVHD. Blood. 2011;117(11):3230-9.

37. Anderson BE, McNiff J, Yan J, Doyle H, Mamula M, Shlomchik MJ, et al. Memory CD4+ T cells do not induce graft-versus-host disease. J Clin Invest. 2003;112(1):101-8.

38. Huang W, Mo W, Jiang J, Chao NJ, and Chen BJ. Donor Allospecific CD44(high) Central Memory T Cells Have Decreased Ability to Mediate Graft-vs.-Host Disease. Front Immunol. 2019;10:624.

39. Carty SA, Koretzky GA, and Jordan MS. Interleukin-4 regulates eomesodermin in CD8+ T cell development and differentiation. PLoS One. 2014;9(9):e106659.

40. Ma J, Wang R, Fang X, and Sun Z. beta-catenin/TCF-1 pathway in T cell development and differentiation. J Neuroimmune Pharmacol. 2012;7(4):750-62.

41. $\mathrm{Yu} \mathrm{Q}$, and Sen JM. Beta-catenin regulates positive selection of thymocytes but not lineage commitment. J Immunol. 2007;178(8):5028-34.

42. Lovatt M, and Bijlmakers MJ. Stabilisation of beta-catenin downstream of T cell receptor signalling. PLoS One. 2010;5(9).

43. MacDonald BT, Tamai $\mathrm{K}$, and $\mathrm{He} \mathrm{X}$. Wnt/beta-catenin signaling: components, mechanisms, and diseases. Dev Cell. 2009;17(1):9-26.

44. Gattinoni L, Zhong XS, Palmer DC, Ji Y, Hinrichs CS, Yu Z, et al. Wnt signaling arrests effector $\mathrm{T}$ cell differentiation and generates CD8+ memory stem cells. Nat Med. 2009;15(7):808-13.

45. Zhao DM, Yu S, Zhou X, Haring JS, Held W, Badovinac VP, et al. Constitutive activation of Wnt signaling favors generation of memory CD8 T cells. J Immunol. 2010;184(3):1191-9.

46. Green DR, Droin N, and Pinkoski M. Activation-induced cell death in T cells. Immunol Rev. 2003;193:70-81.

47. Schroeder MA, and DiPersio JF. Mouse models of graft-versus-host disease: advances and limitations. Dis Model Mech. 2011;4(3):318-33.

48. Bouazzaoui A, Spacenko E, Mueller G, Miklos S, Huber E, Holler E, et al. Chemokine and chemokine receptor expression analysis in target organs of acute graft-versus-host disease. Genes Immun. 2009;10(8):687-701.

49. Blazar BR, Taylor PA, Panoskaltsis-Mortari A, Gray GS, and Vallera DA. Coblockade of the LFA1:ICAM and CD28/CTLA4:B7 pathways is a highly effective means of preventing acute lethal graft-versus-host disease induced by fully major histocompatibility complex-disparate donor grafts. Blood. 1995;85(9):2607-18.

50. Liu T, Zhang L, Joo D, and Sun SC. NF-kappaB signaling in inflammation. Signal Transduct Target Ther. 2017;2.

51. Sun SC. The non-canonical NF-kappaB pathway in immunity and inflammation. Nat Rev Immunol. 2017;17(9):545-58.

52. Herrington FD, Carmody RJ, and Goodyear CS. Modulation of NF-kappaB Signaling as a Therapeutic Target in Autoimmunity. J Biomol Screen. 2016;21(3):223-42.

53. Saidu NEB, Bonini C, Dickinson A, Grce M, Inngjerdingen M, Koehl U, et al. New Approaches for the Treatment of Chronic Graft-Versus-Host Disease: Current Status and Future Directions. Front Immunol. 2020;11:578314. 
945 54. Vodanovic-Jankovic S, Hari P, Jacobs P, Komorowski R, and Drobyski WR. NF-kappaB as a target for the prevention of graft-versus-host disease: comparative efficacy of bortezomib and PS-1145. Blood. 2006;107(2):827-34.

55. Shimabukuro-Vornhagen A, Hallek MJ, Storb RF, and von Bergwelt-Baildon MS. The role of $\mathrm{B}$ cells in the pathogenesis of graft-versus-host disease. Blood. 2009;114(24):4919-27.

56. Augello G, Emma MR, Cusimano A, Azzolina A, Montalto G, McCubrey JA, et al. The Role of GSK-3 in Cancer Immunotherapy: GSK-3 Inhibitors as a New Frontier in Cancer Treatment. Cells. 2020;9(6).

956

57. Zhang $\mathrm{Y}$, and Wang X. Targeting the Wnt/beta-catenin signaling pathway in cancer. $J$ Hematol Oncol. 2020;13(1):165. 
A

H

6

6

12

19

19

26

32

41

55

18

$++$

8Death by GVL †Death by GVHD

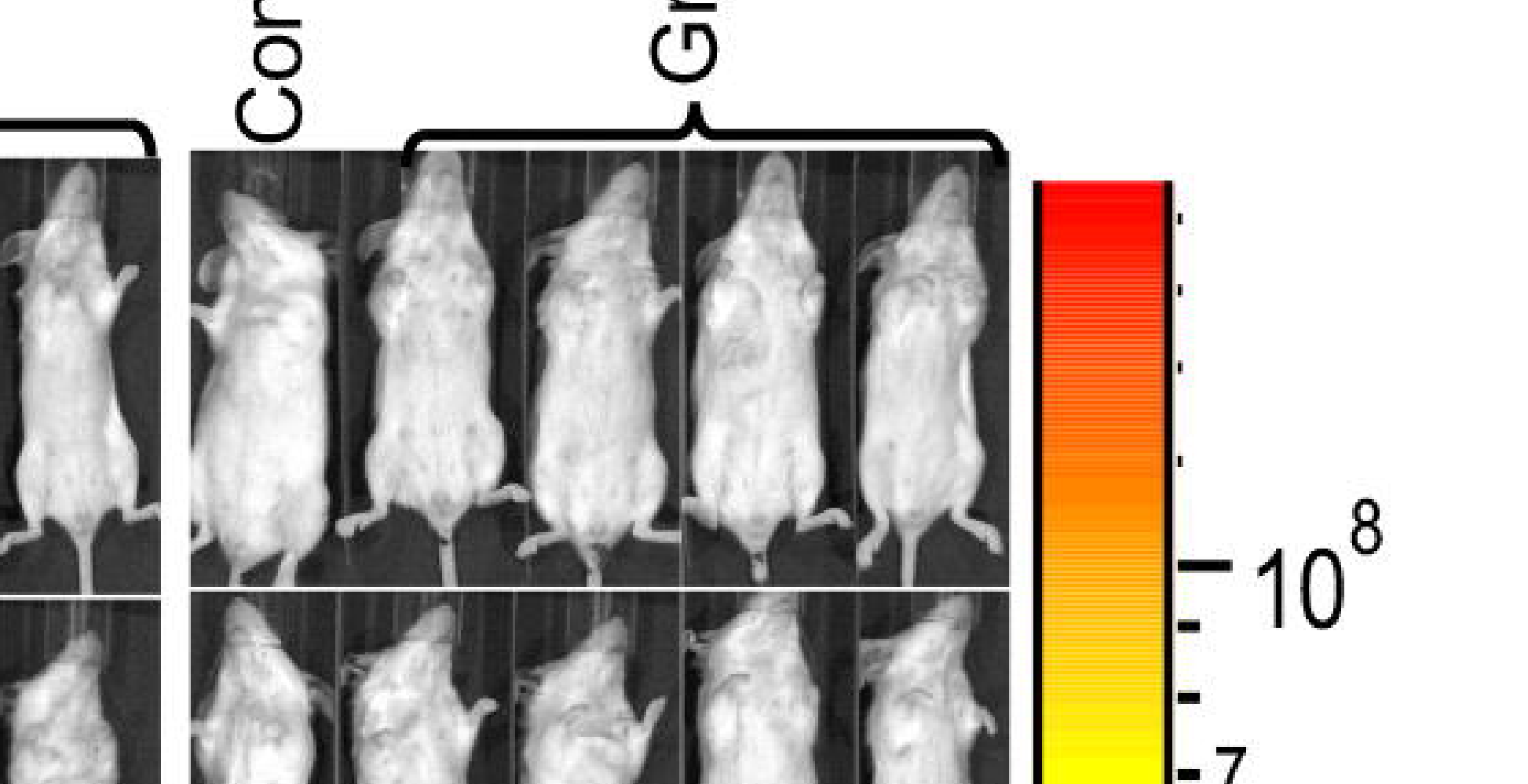

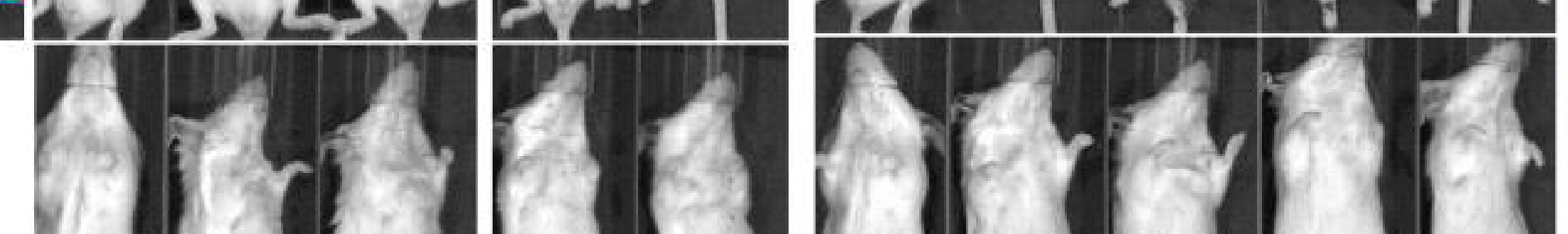

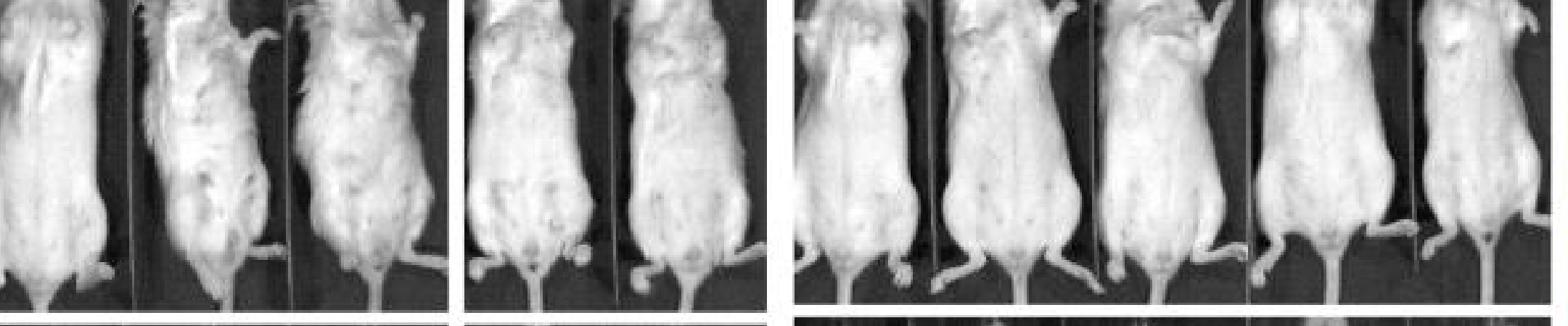

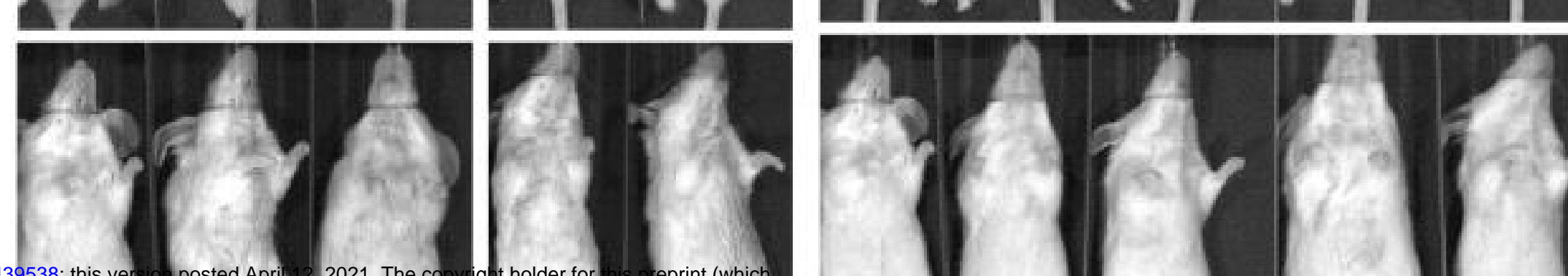

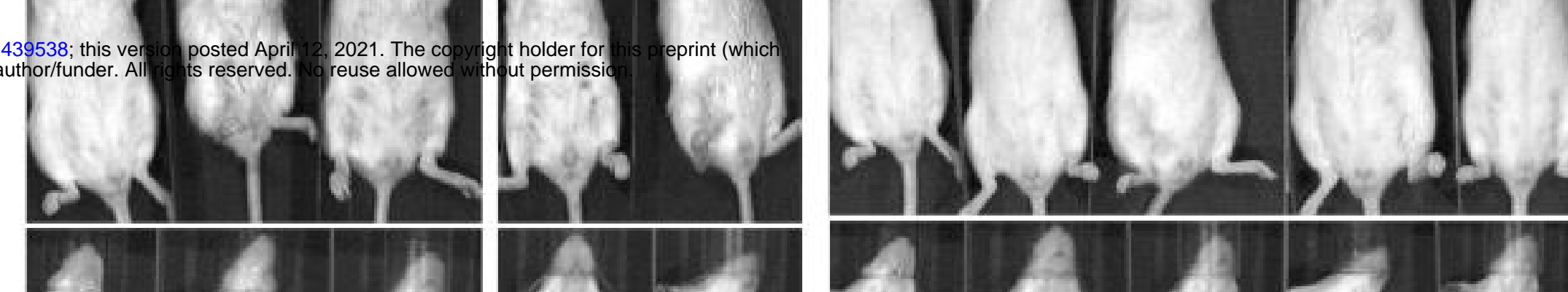

1y) 1112

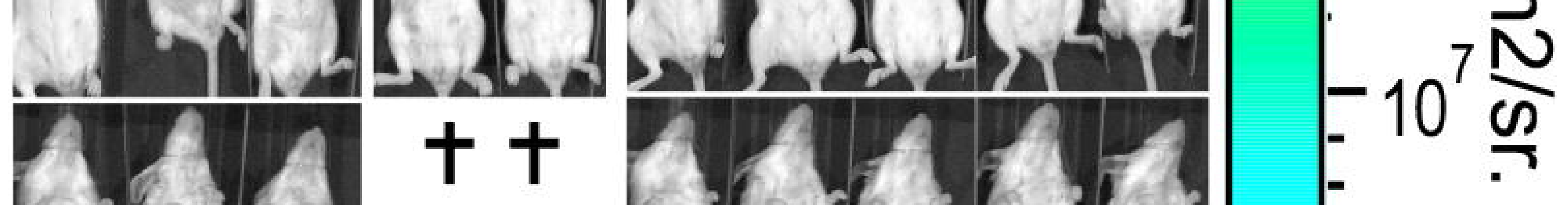

- TCD BM Group1

TCD BM B-ALL Iuc Group2

B

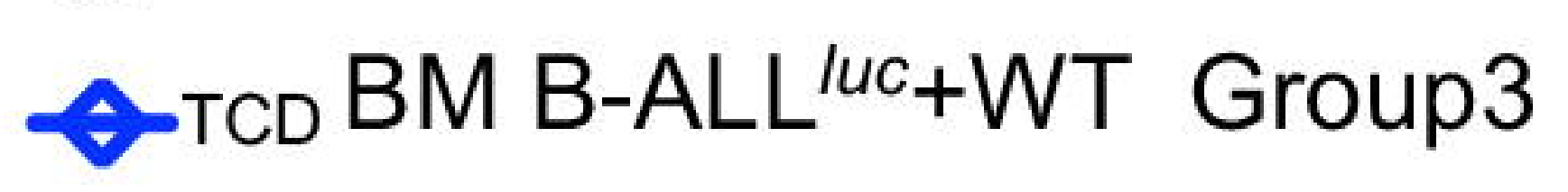

$\sim-\mathrm{TCD}$ BM B-ALL ${ }^{l u c}+$ Cat-Tg Group4

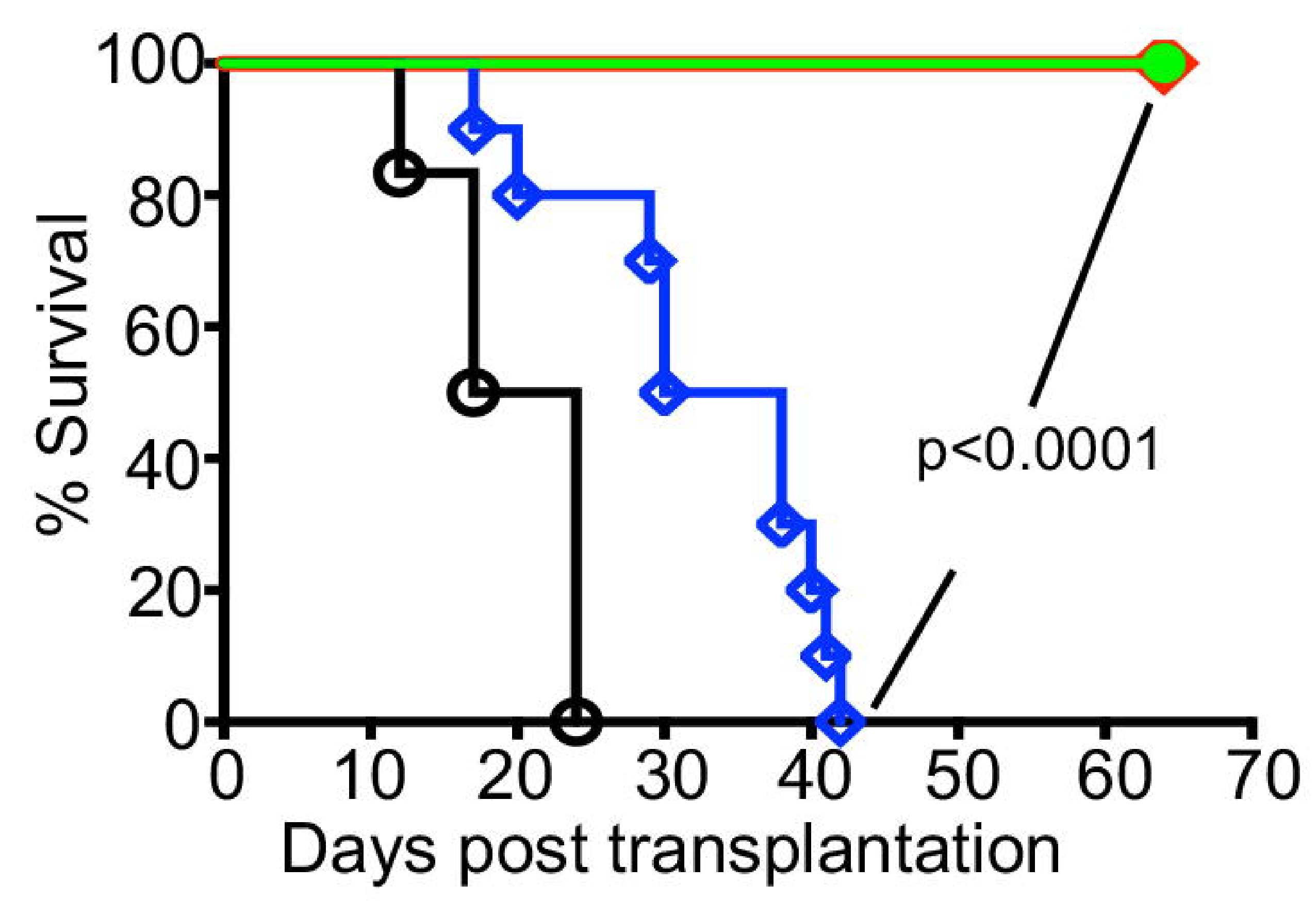

C

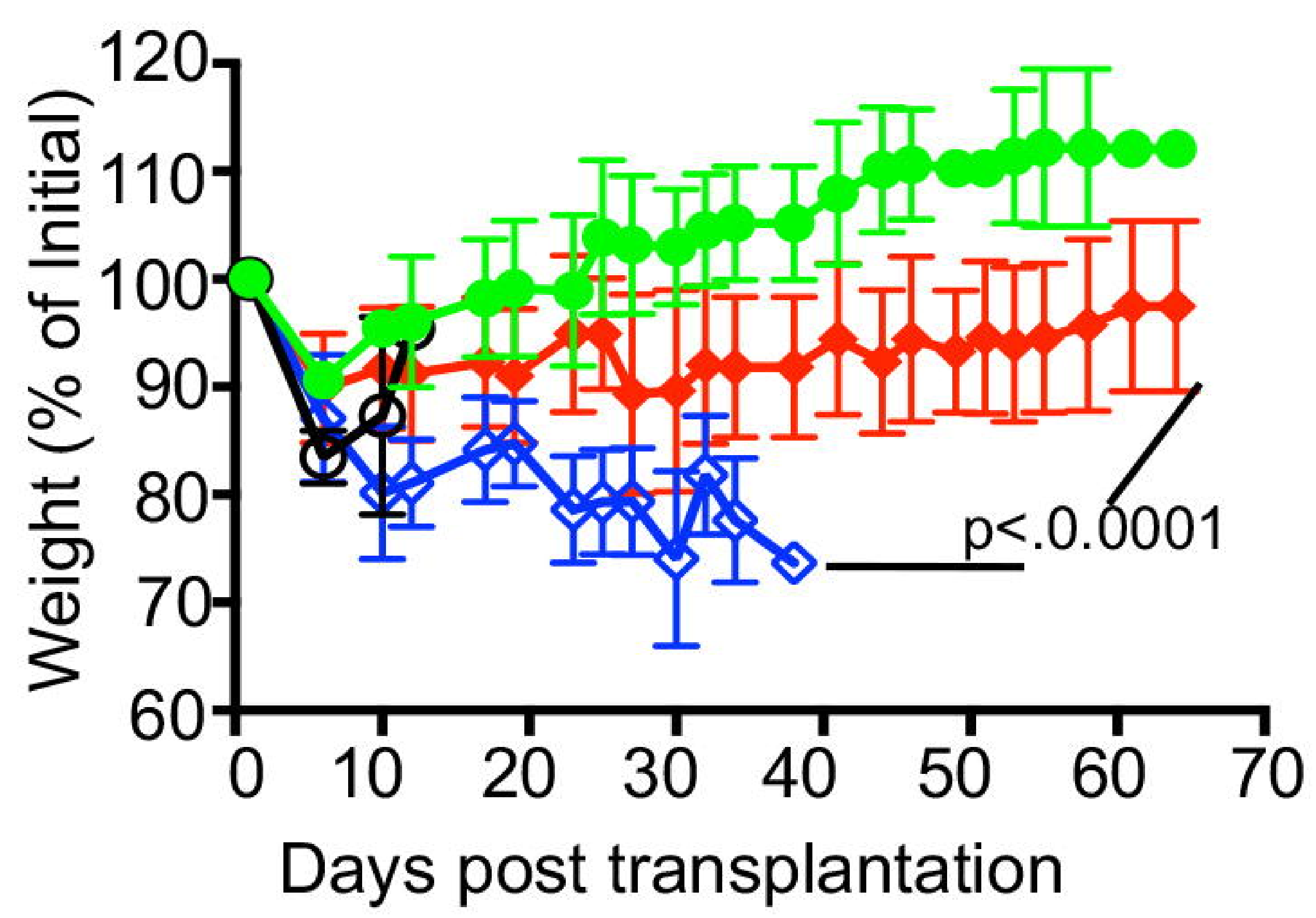

D

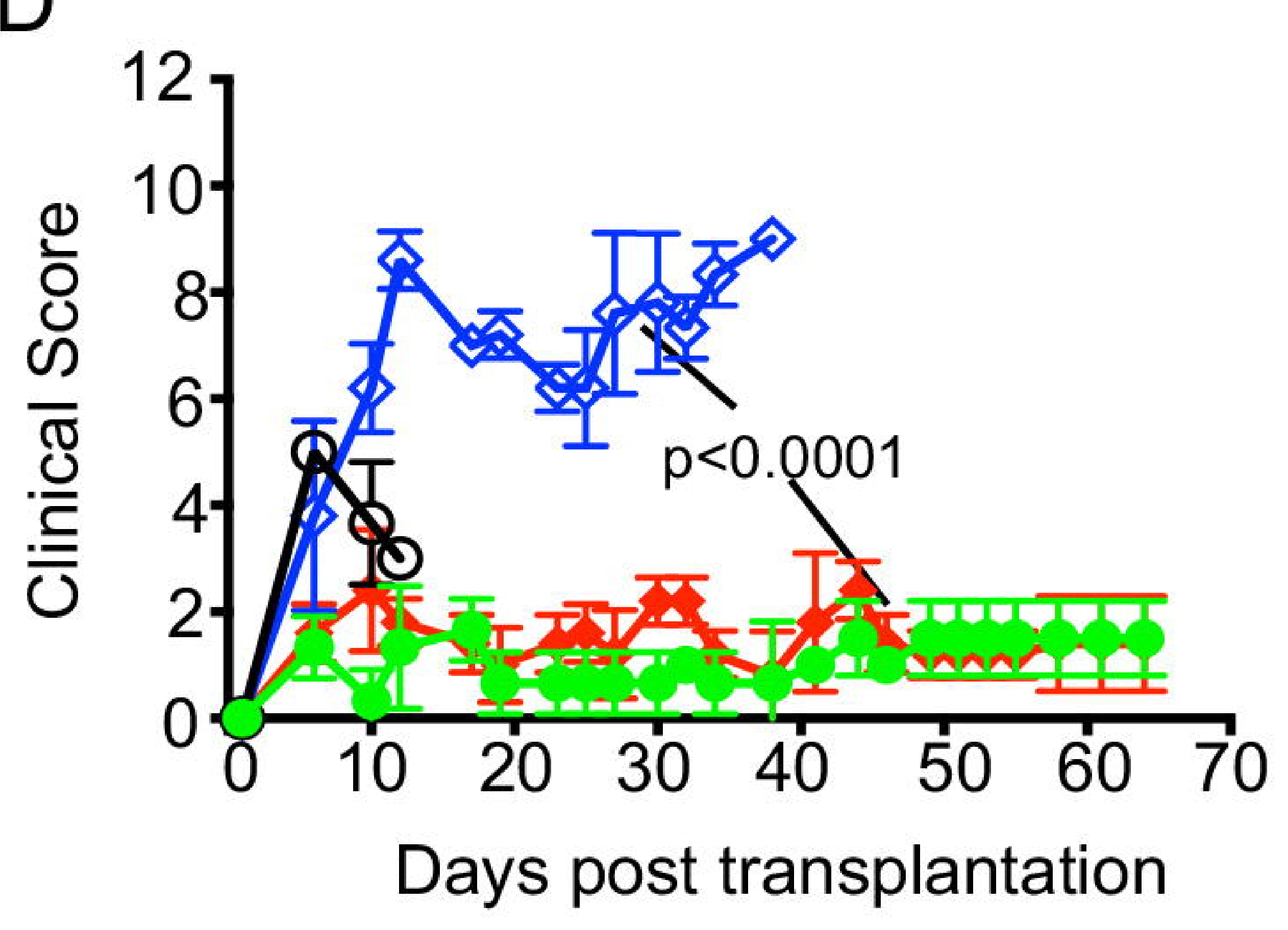




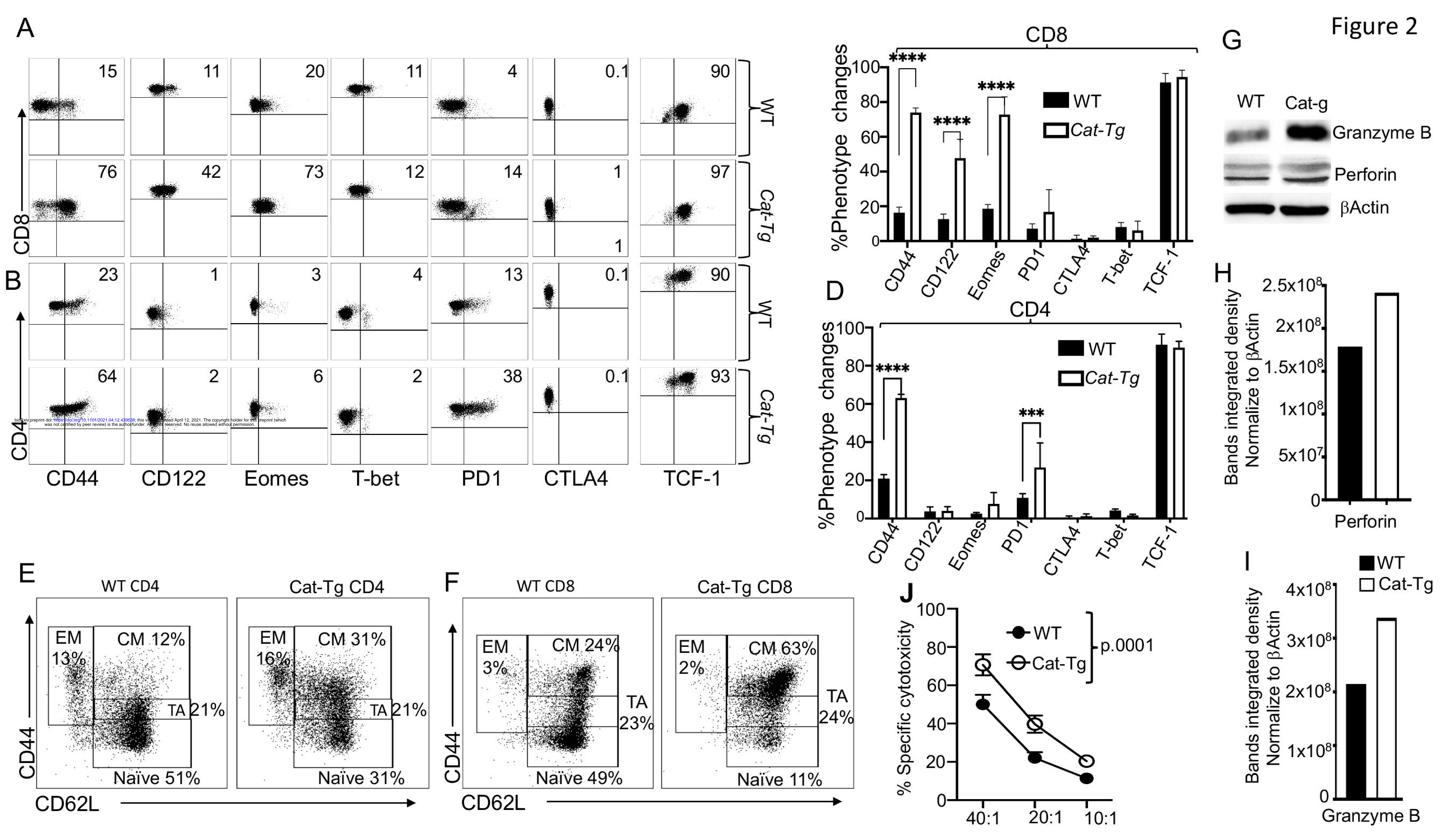




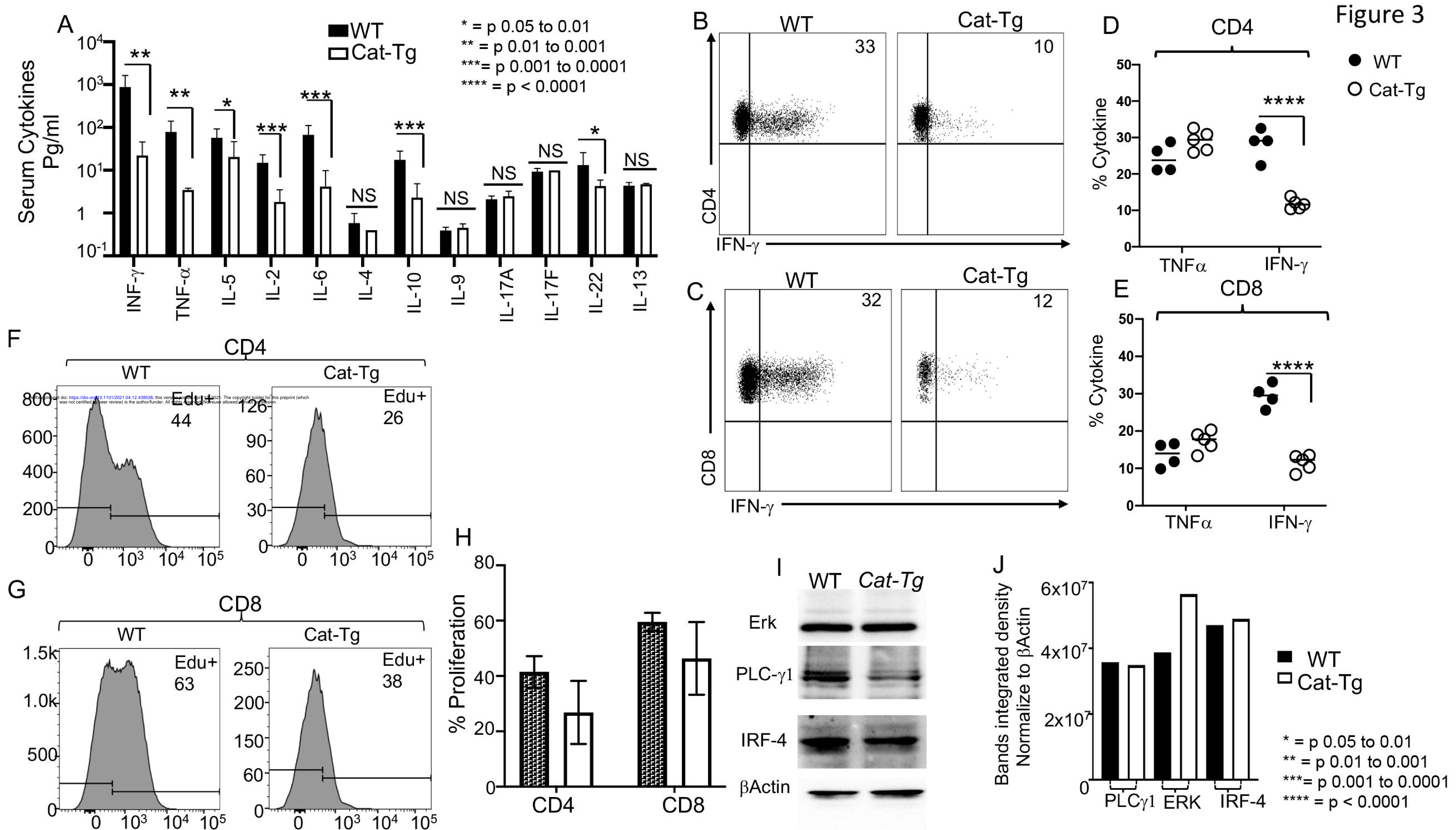




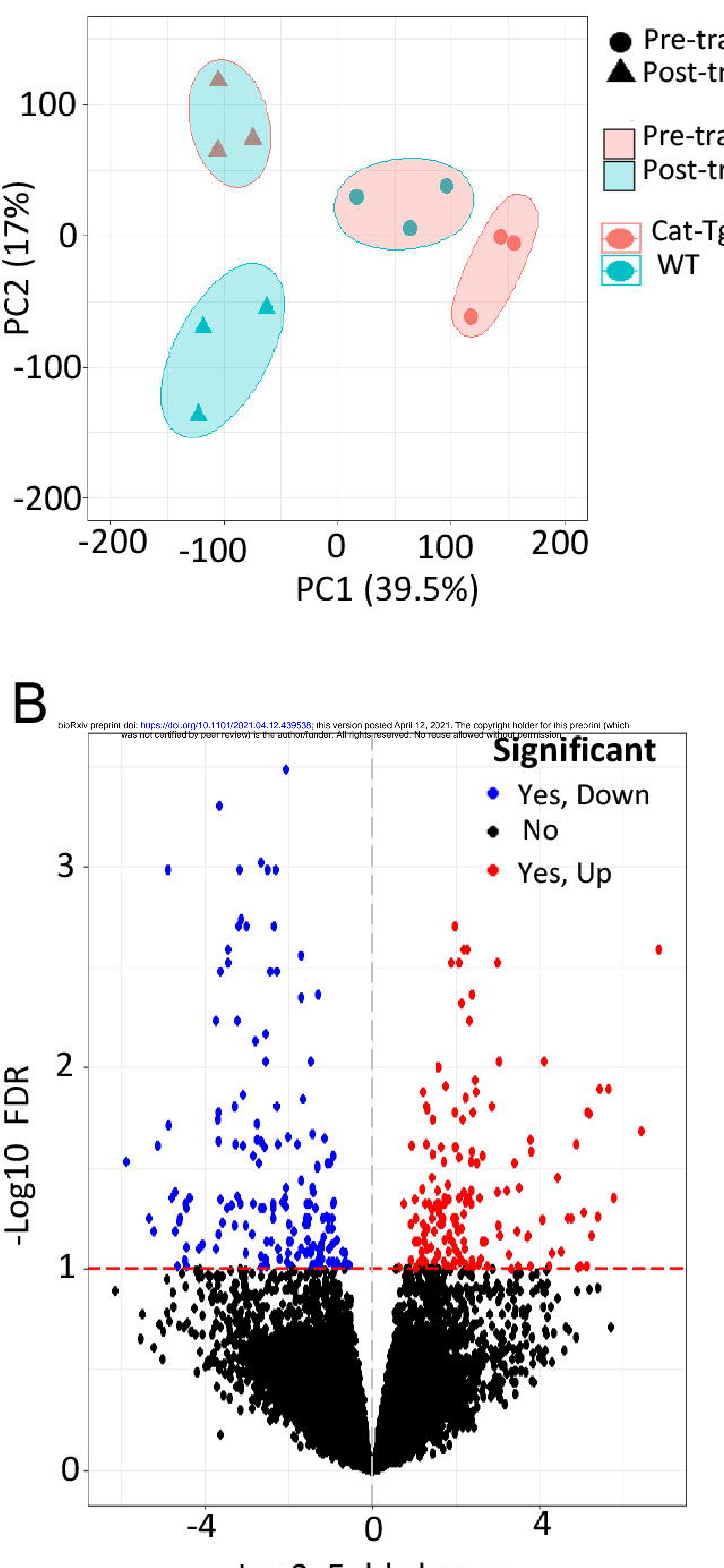

Log2 Fold change
Color key
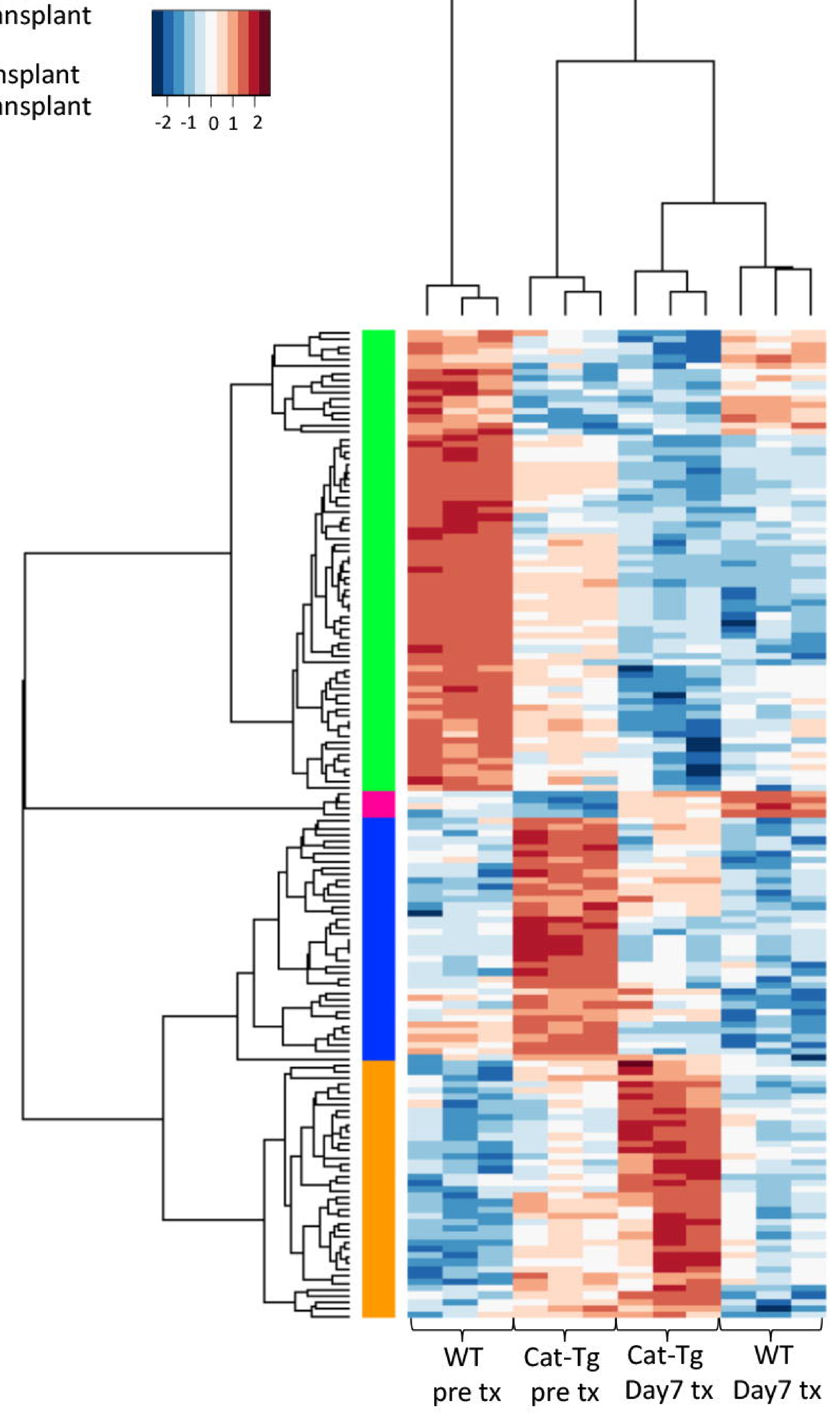

D

Figure 4
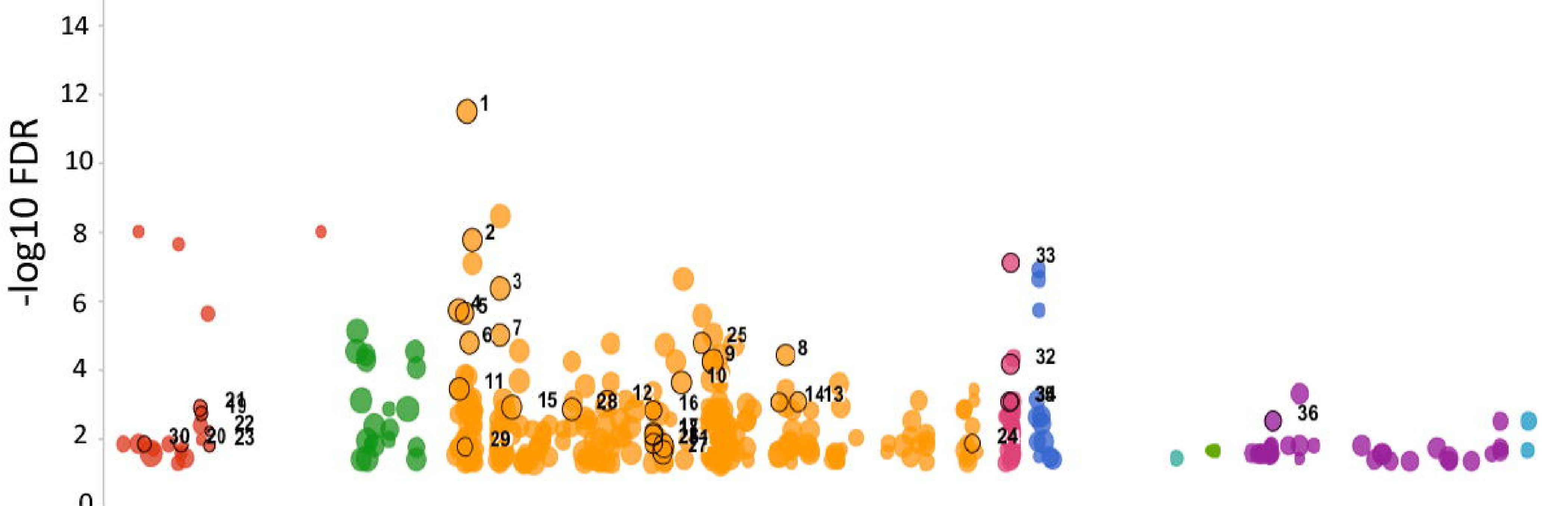

言
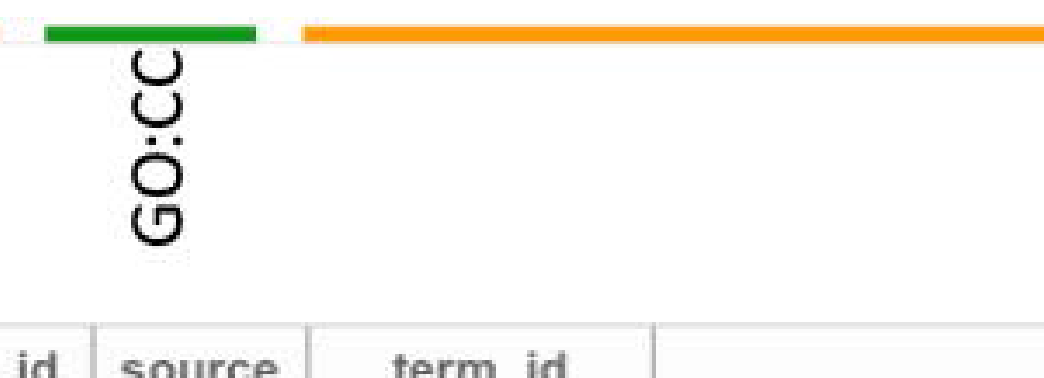

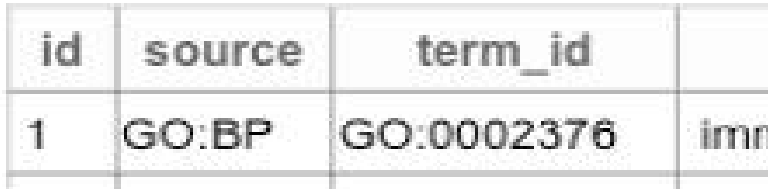
8

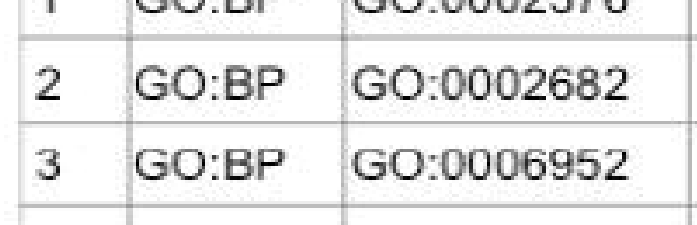

GO:BP 60:0001775

\begin{tabular}{|l|l|l|}
\hline 5 & $60: B P$ & $60: 0002250$ \\
\hline 6 & $60: B P$ & $60: 0002520$ \\
\hline 7 & $6: B P$ & 6000254
\end{tabular}

\begin{tabular}{|l|l|l|}
\hline 6 & $60: B P$ & $60: 0002520$ \\
\hline 7 & $60: B P$ & $60: 0006954$ \\
\hline
\end{tabular}

\begin{tabular}{|c|c|c|}
\hline 8 & $60: B P$ & $60: 0070661$ \\
\hline 9 & $60: B P$ & $60: 0048583$ \\
\hline & 600 & 000458 \\
\hline
\end{tabular}

11 GO:BP $\quad$ GO:0001816 cytokine productor

12 GO:BP $\quad 60: 0032680$ regulation of tumor necrosis factor production

$\begin{array}{cccc}13 & 60: B P & 60: 0071706 & \text { tumor necrosis factor superfamily cytokine } \\ 14 & \text { GO:BP } & \text { GO:0070098 } & \text { chemokine-mediated signaling pathway } \\ 15 & \end{array}$

16 GO:BP G0:0042102 positive regulation of $T$ cell proliferation

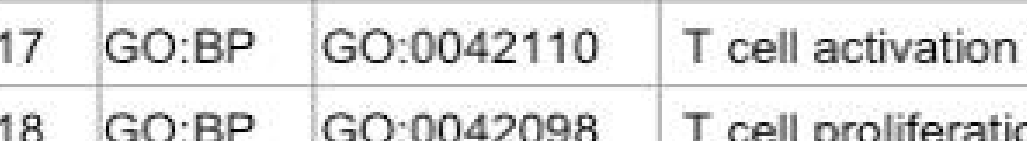

19 GO:MF G0:0023023 MHC protein complex binding

20 GO:MF G0:0016493 C.C chemokine receptor activivy

21 GO:MF GO:0019957 C-C chemokine binding

$\begin{array}{llll}22 & \text { GO:MF } & 60: 0031726 & \text { CCR1 chomokine rocoptor binding } \\ 23 & \text { GO:MF } & 60.0031730 & \text { CCR5 chemokine receptor binding }\end{array}$

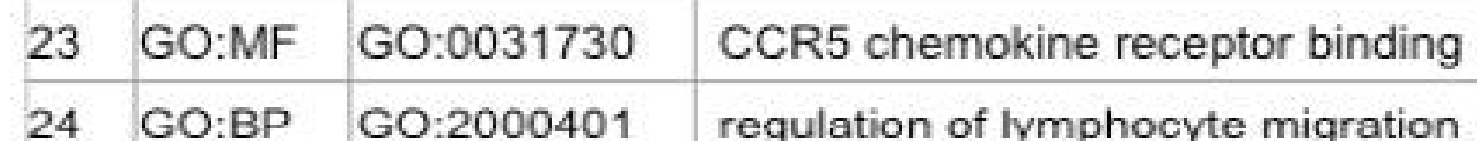

$\begin{array}{lllll}24 & \text { CO:BP } & 60: 2000401 & \text { regulation of } y m p h o c y t e \\ 25 & 60: B P & 60: 0046551 & \text { Iymphocyte proliferation }\end{array}$

$\begin{array}{lllll}26 & 60: B P & 60: 0042129 & \text { regulation of } T \text { cell proiliferation }\end{array}$

$\begin{array}{llll}27 & 60: B P & 60: 0042981 & \text { regulation of apoptotic process }\end{array}$

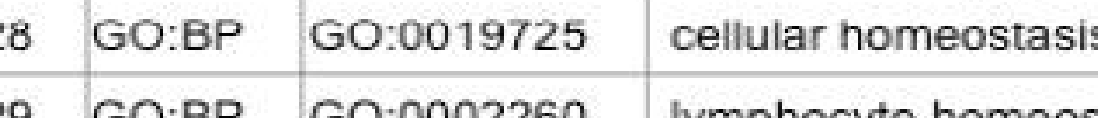

\begin{tabular}{lll}
9 & $60: B P$ & $60: 00022$ \\
0 & $60: M F$ & $60: 00049$ \\
\hline
\end{tabular}

$\begin{array}{llll}31 & 60: B P & 60: 0043067 & \text { regulation of programmed cell de }\end{array}$

32 KEGG KEGG:04514 Cell adhesion molecules

34 KEGG KEGG:044672

(I) intestinal immune network for

${ }_{36}$ HP HP.0002950 Autimmuntryaty pathw 


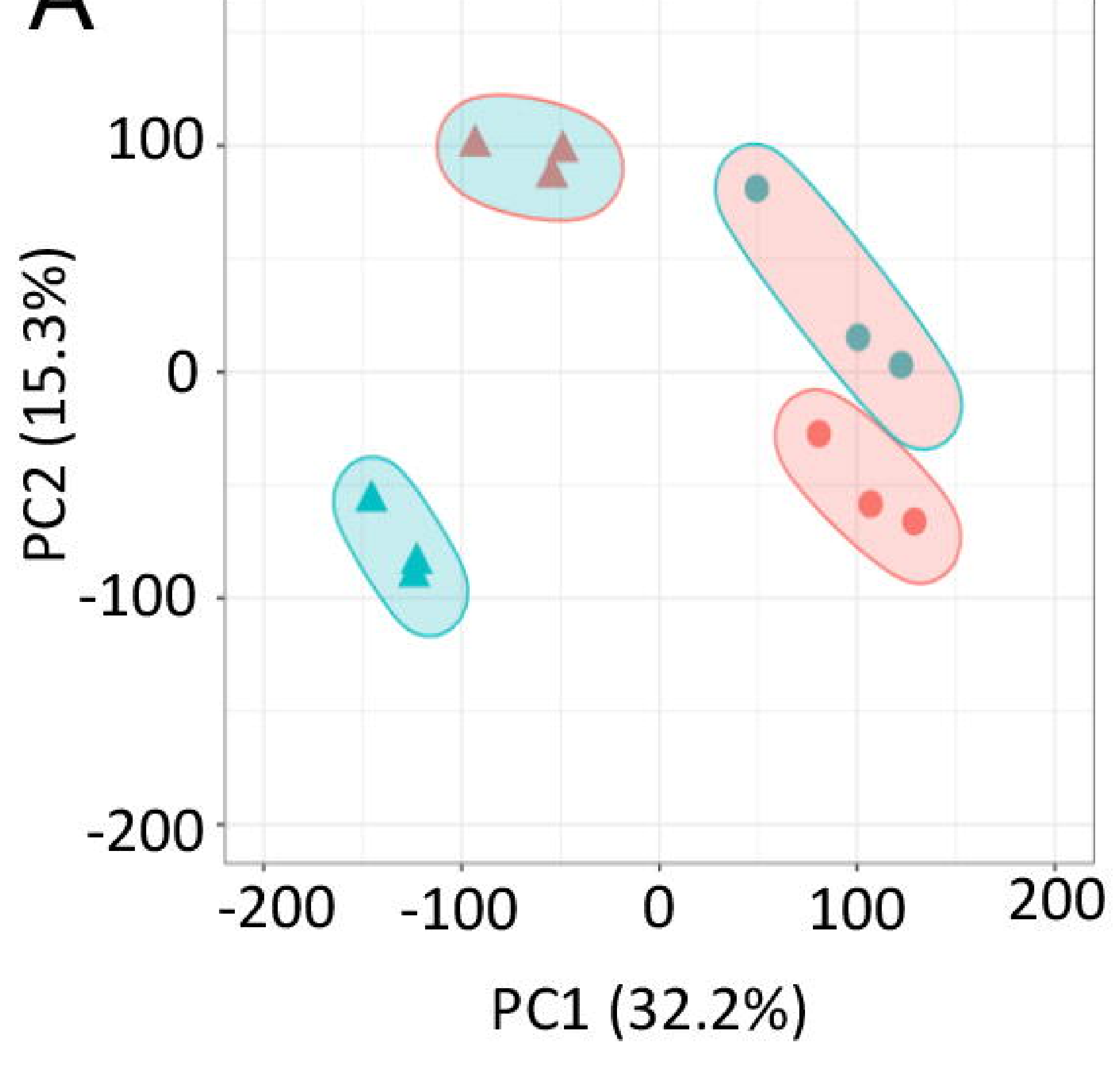

$\mathrm{B}$

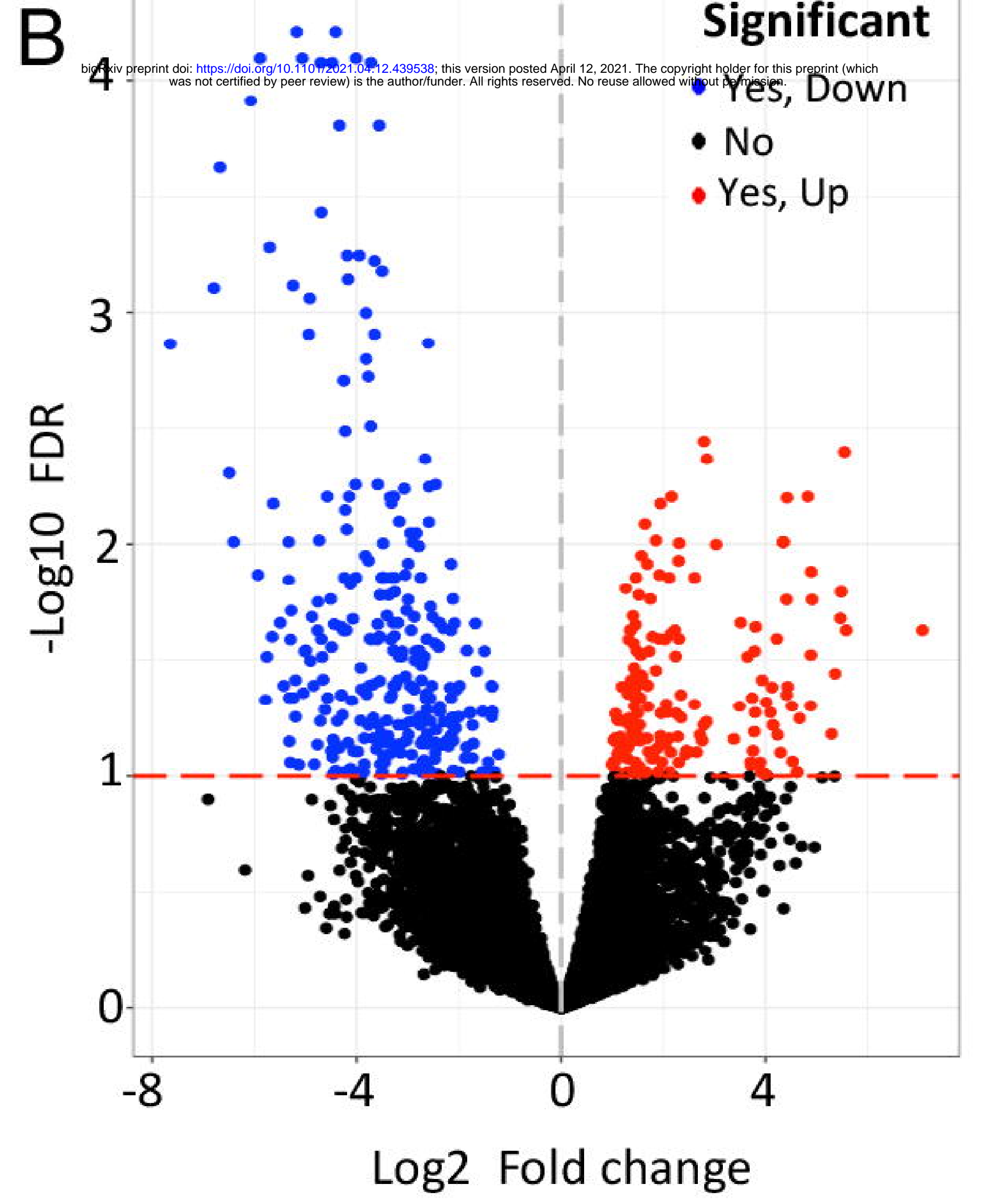

Log2 Fold change
- Pre-transplant

Cost-transplan

\begin{tabular}{|l}
$\square$ Pre-transplant \\
$\square$ Post-transplant
\end{tabular}

Cat-Tg

WT

Color key
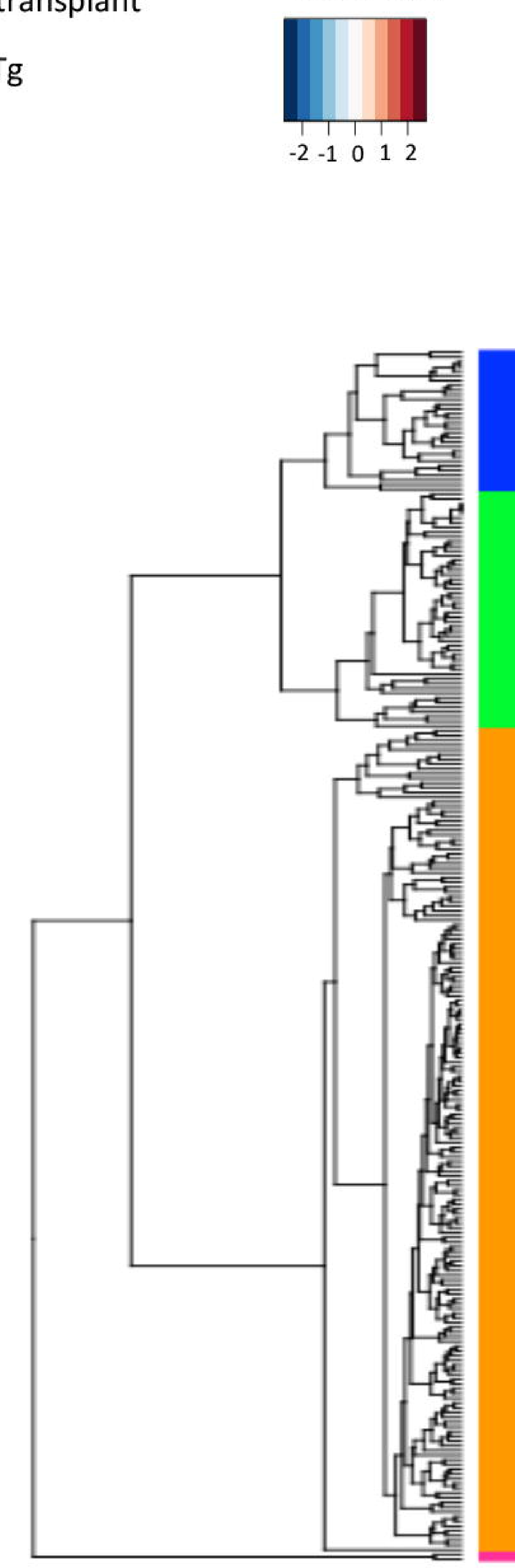

Figure 5

Values above threshold are capped

$0^{7} \quad 8^{8}$

은 10

$\stackrel{1}{\circ}{ }_{0}^{\circ} 8$

은 6 .

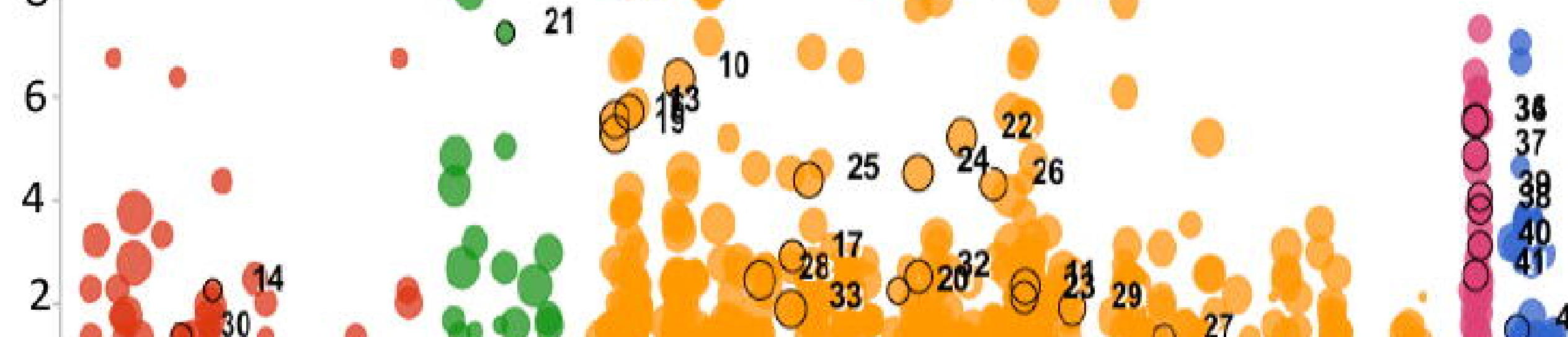

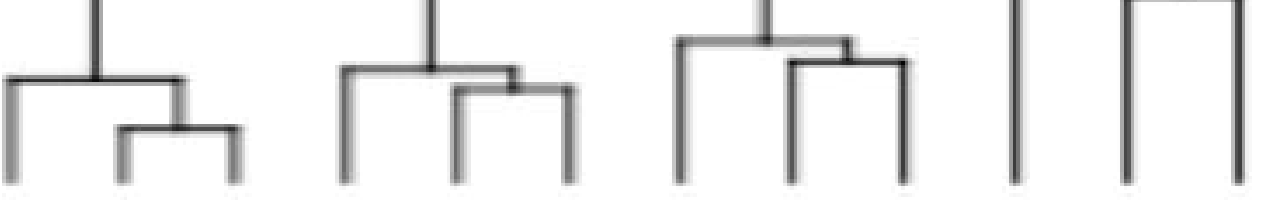
0
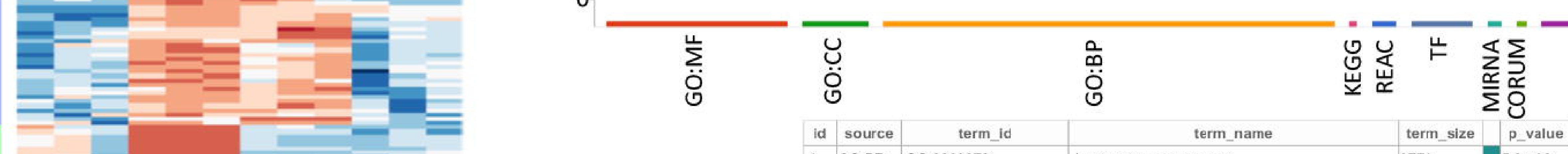

$\infty 8$

sis

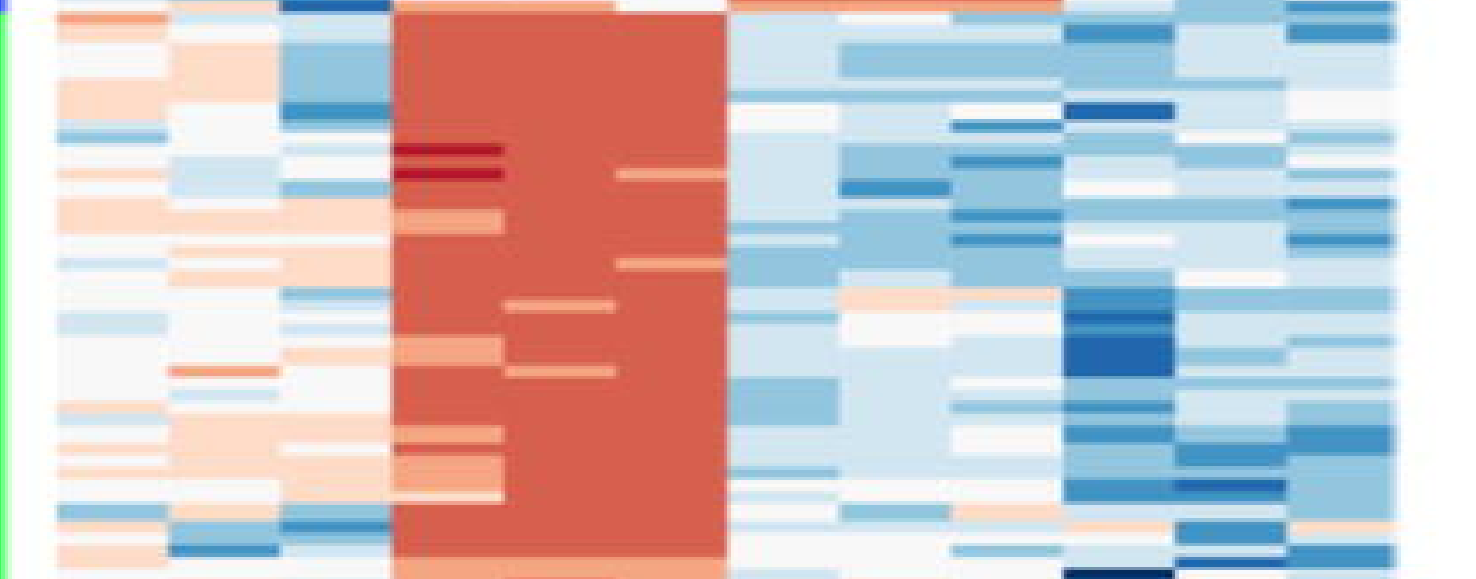

$\begin{array}{lll}\text { id } \text { source } & \text { term_Id } \\ 1 & 60: B P & 60: 0002376\end{array}$

term_name

오

高

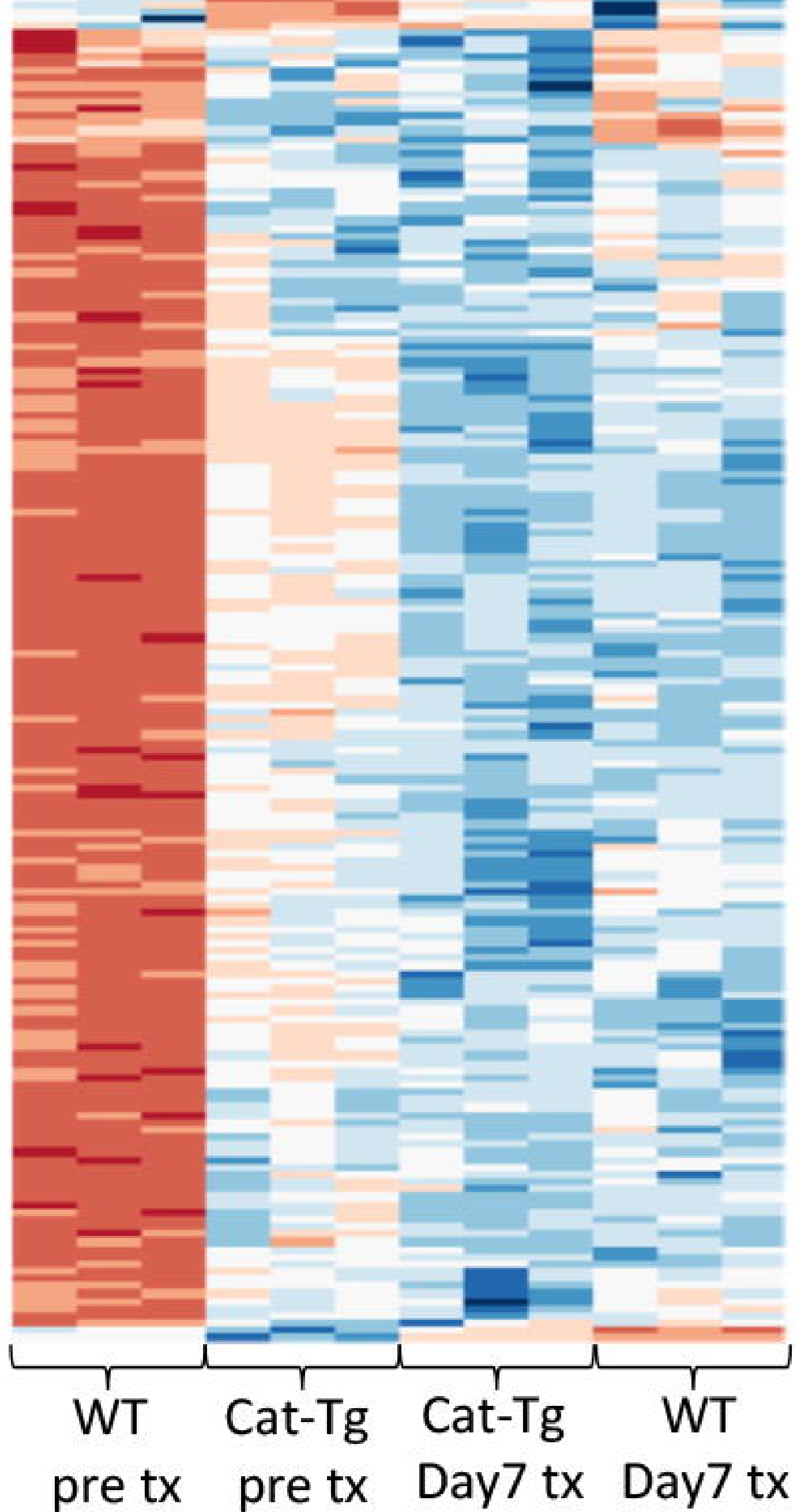

\begin{tabular}{llll}
\hline & GO:BP & $60: 0045321$ \\
\hline 5 & $G O: B P$ & $60: 0046649$ \\
\hline & CO:BP & 0000625
\end{tabular}

\begin{tabular}{lll}
6 & $60: B P$ & $60: 0002250$ \\
7 & GO:BP & $60: 0042113$ \\
\hline
\end{tabular}

\begin{tabular}{llll}
78 & $60: 8 P$ & $60: 0050778$ \\
\hline 9 & $60: 8 P$ & $60: 0002764$ \\
\hline
\end{tabular}

$\begin{array}{lll}10 & 60: B P & 60: 0006952 \\ 10 & 60: P P & 60.05590\end{array}$

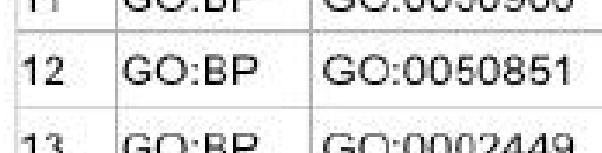

14 GO:MF $\quad 60: 0023023$

$\begin{array}{lll}50: B P & 60: 0002757\end{array}$

\begin{tabular}{cccc}
17 & $60: B P$ & $60: 0019882$ \\
18 & $6:-8 P$ & 600002521 \\
\hline
\end{tabular}

19 GO:BP $\quad$ G0:0001817

\begin{tabular}{llll}
20 & $60.6 P$ & 60.0036037 \\
21 & $60.0 \mathrm{CC}$ & 60.0042613 \\
\hline
\end{tabular}

\begin{tabular}{lll} 
Go:BP & $60: 0045087$ \\
\hline 3 & G0:BP & $60: 0050552$ \\
\hline
\end{tabular}

$\begin{array}{lll}24 & 60: B P & 60: 0002110 \\ 25 & 00: B P & 60: 0022407\end{array}$

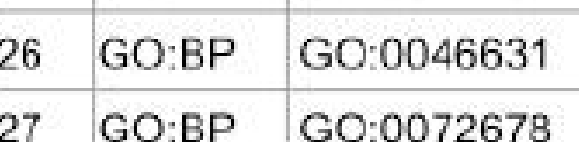

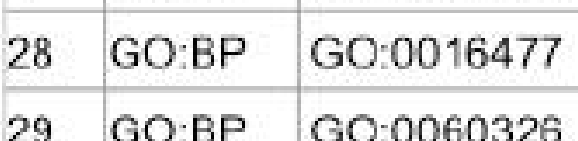

\begin{tabular}{lll}
30 & GO:MF & $60: 0016493$ \\
31 & GO:BP & 60.0046651 \\
\hline
\end{tabular}

\begin{tabular}{lll}
$260: B P$ & $60: 0042129$ \\
3 & $60: B P$ & $60: 0019725$ \\
\hline
\end{tabular}

\begin{tabular}{lll}
34 & KEGG & KEGG:04514 \\
35 & KEGG & KEGG:04640 \\
\hline 3 & K
\end{tabular}

\begin{tabular}{lll}
35 & KEGG & KEGG:04640 \\
36 & KEGG & KEGG:04658 \\
\hline
\end{tabular}

$\begin{array}{lll}36 & \text { KEGG } & \text { KEGG:04658 } \\ 37 & \text { KEGG } & \text { KEGG:04659 }\end{array}$

\begin{tabular}{lll}
38 & KEGG & KEGG:05321 \\
39 & KEGG & KEGG:05330 \\
\hline
\end{tabular}

\begin{tabular}{lll}
$*$ & KEGG & KEGG:05332 \\
\hline KEGG & KEGG:04660
\end{tabular}

cel activation

\begin{tabular}{|l|} 
Iymphocyte activation \\
adaptive immune ress \\
\hline
\end{tabular}

positive regulatioto of i immune response

defenser response

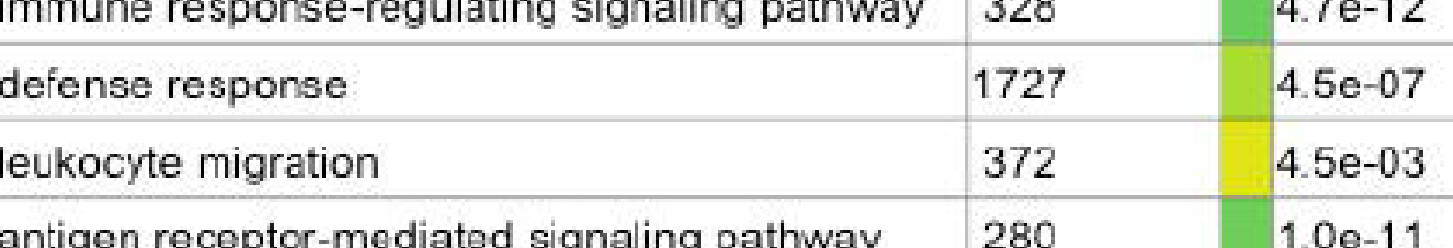

$\begin{array}{lll} & 1.00-11 \\ & 300\end{array}$

MHC protein complex binding

cyiokine production

anigigen processing and present
leukocyte differentitition

regulation of cyokokine production
CDB-positive, alpha-beta T Tiof

MHC class II protein complex

T cell recepptor signalin

T cell activation

alpha-beta T cell active

\begin{tabular}{|l} 
cell migration \\
cell chemotaxis \\
\hline CEl
\end{tabular}

Iymphocote profiferation activiy

regulaton of T cell prolitit
colular homoostasis

Cell achesion molecules

Allograt rejection

Graft-versus-host disease
Tcell recentor signaing

\begin{tabular}{lcc} 
& 55 & $84 e-05$ \\
\hline & 100 & $28 \mathrm{e}-04$ \\
\hline
\end{tabular} 


\section{A}

Pre-transplanted
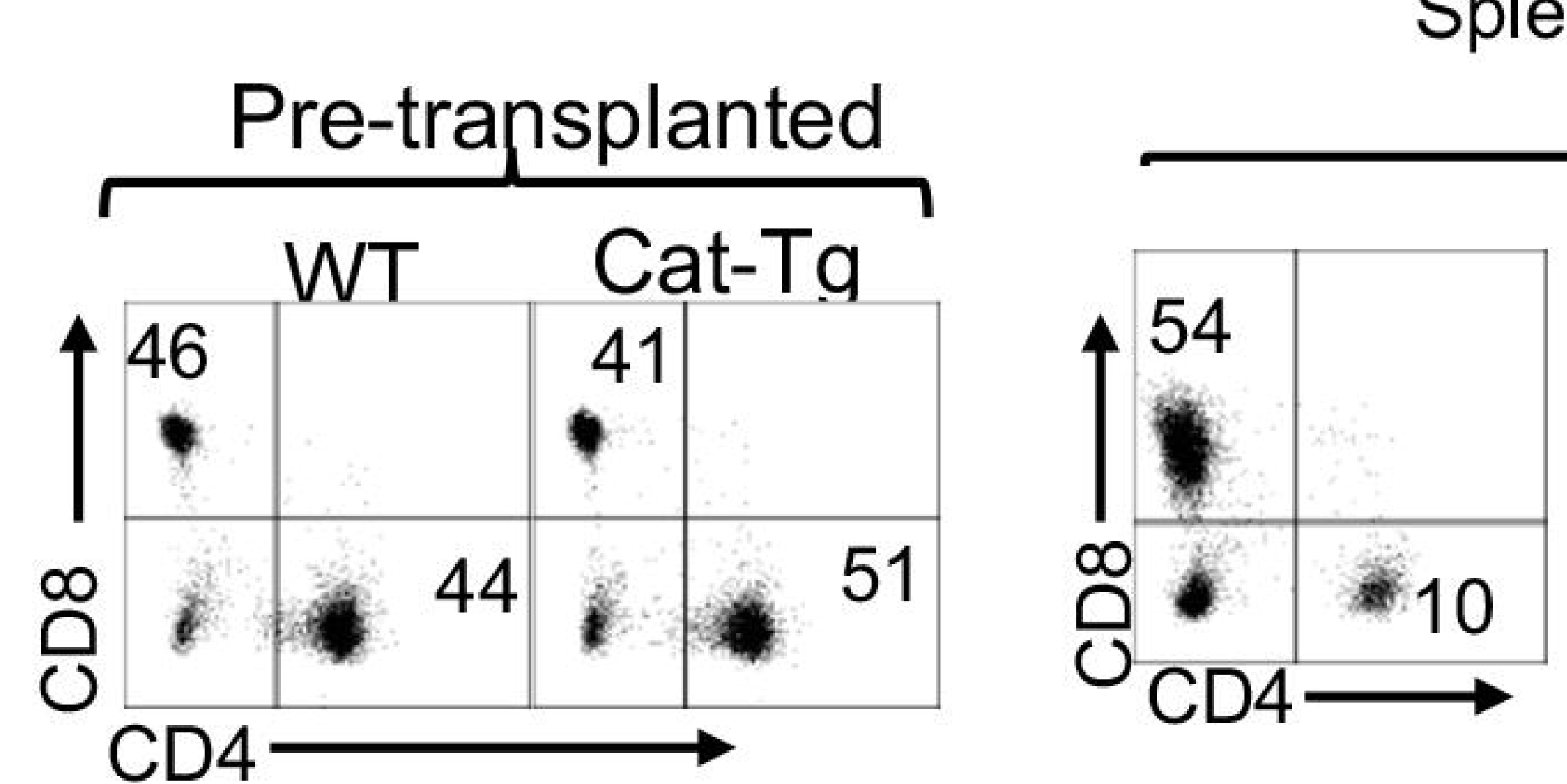
WT:WT

C
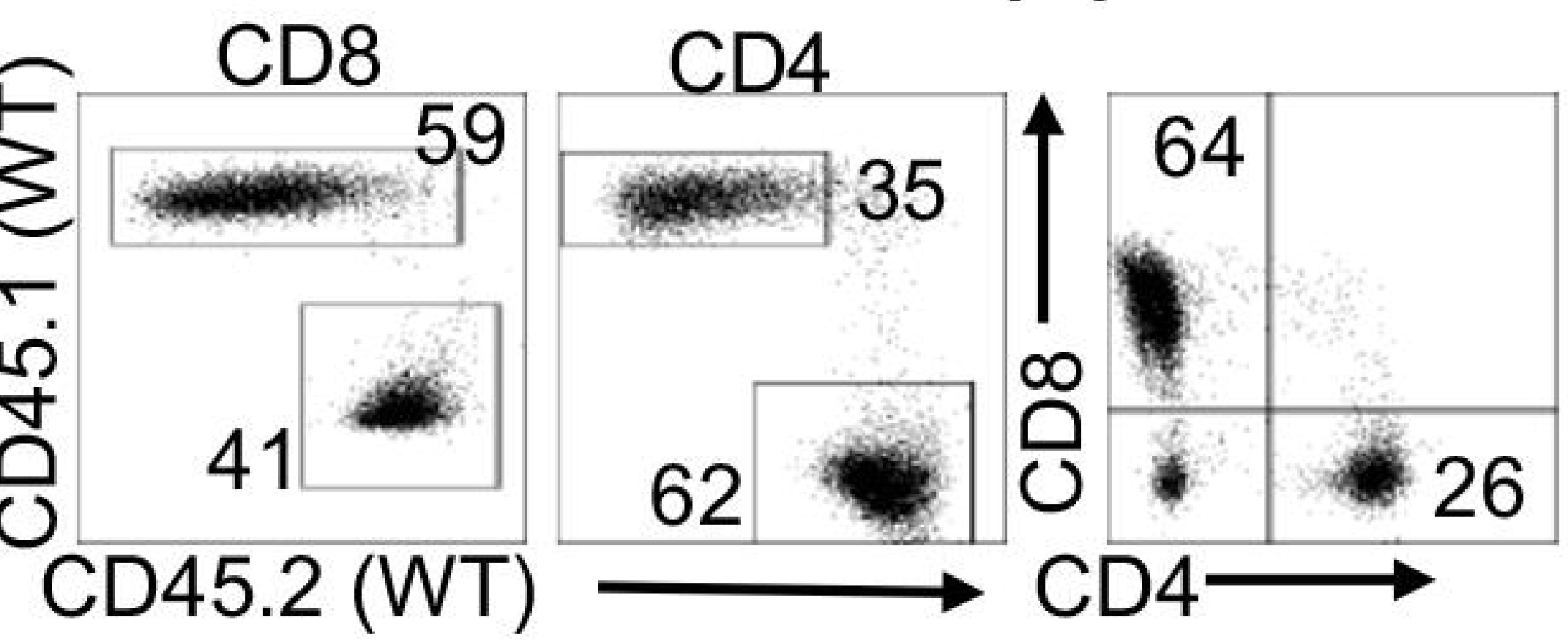

Liver post transplanted WT:WT

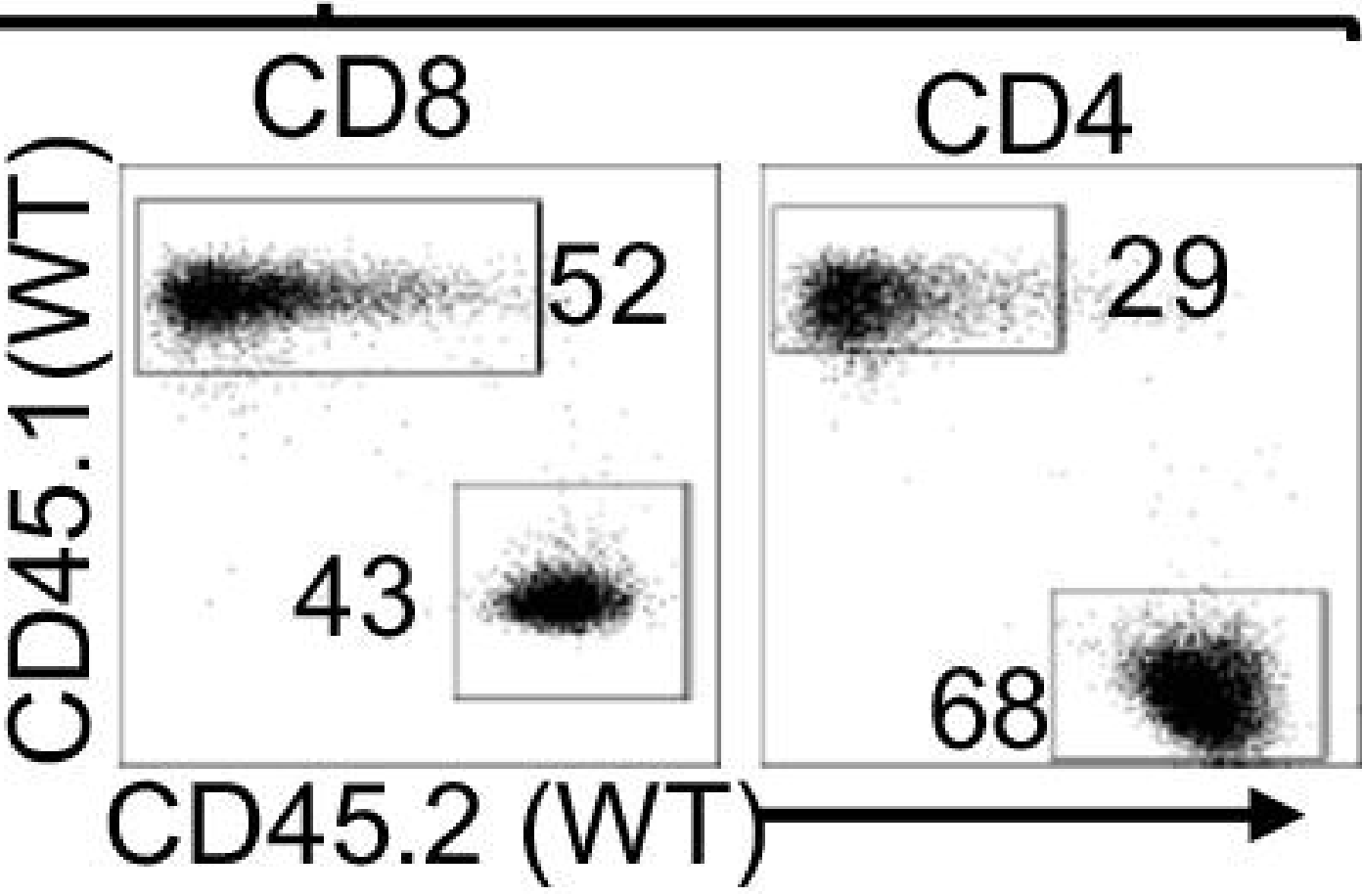

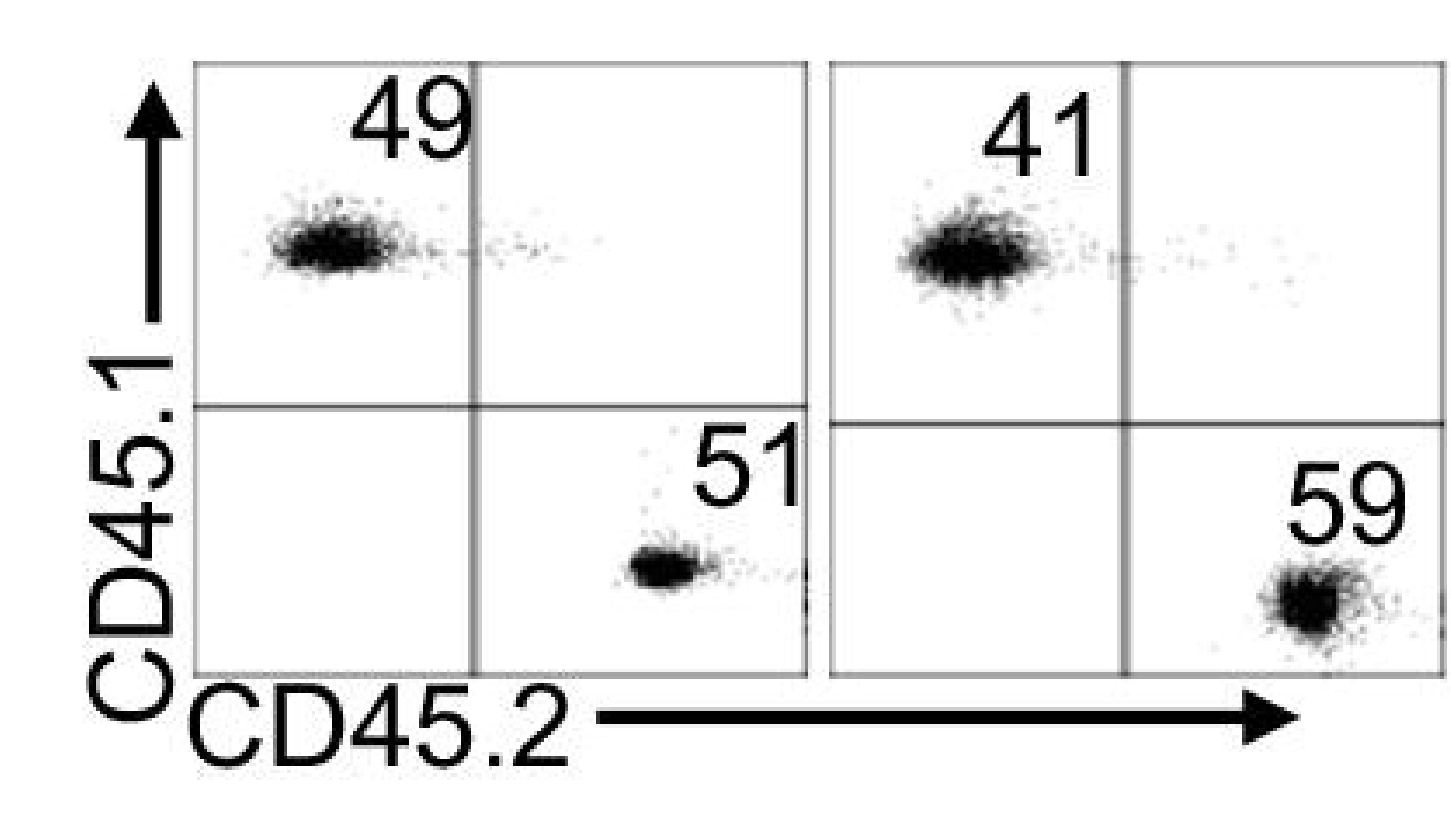

$\longrightarrow$

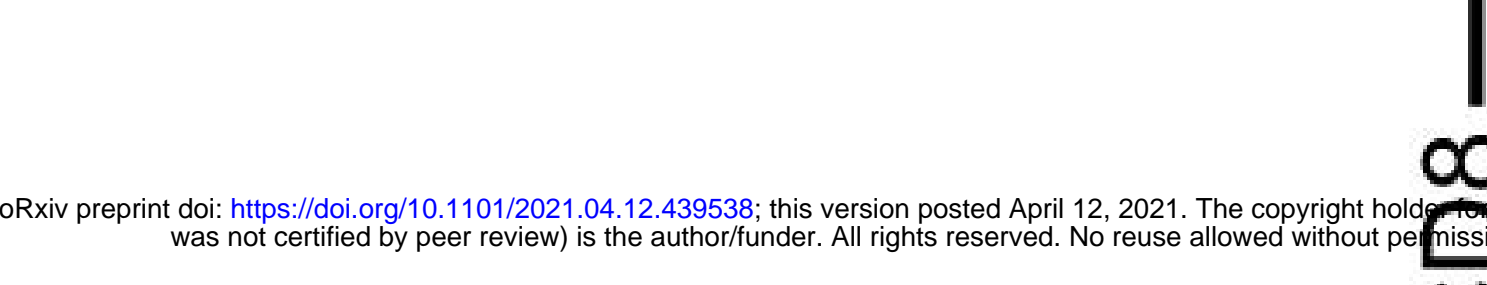

D

Spleen post-transplanted WT: Cat-Tg
Spleen post-transplanted

G

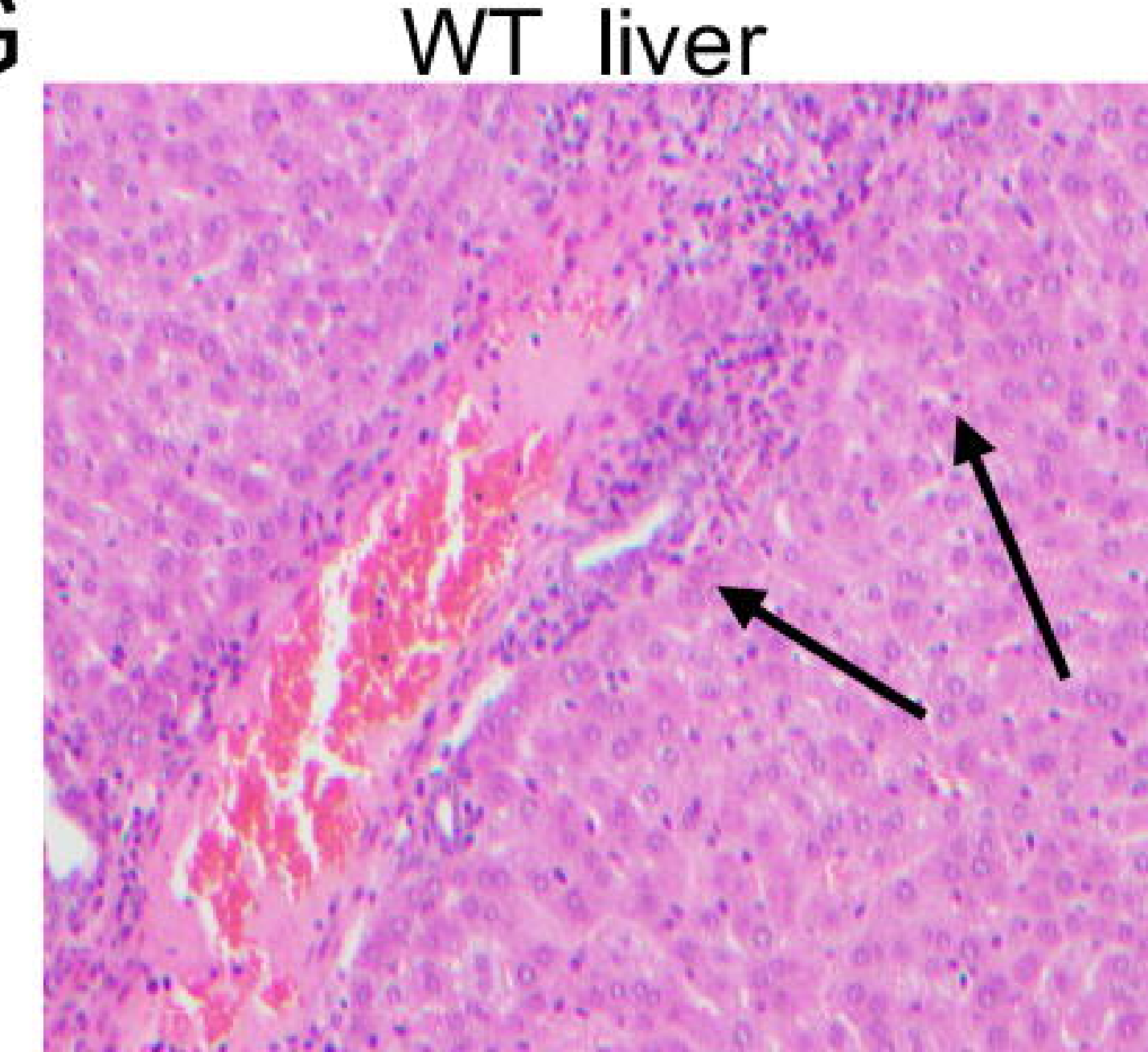

WT SI

Liver post transplanted

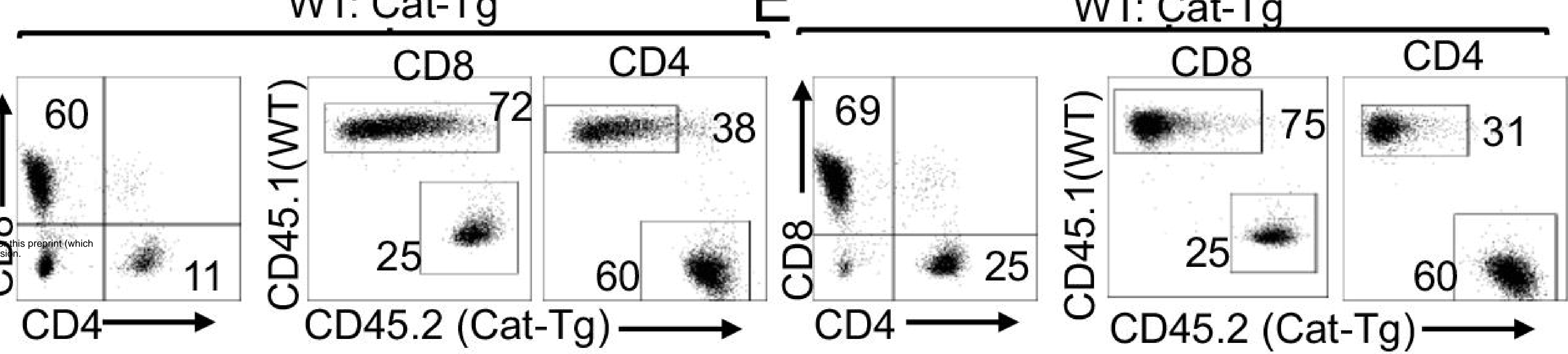

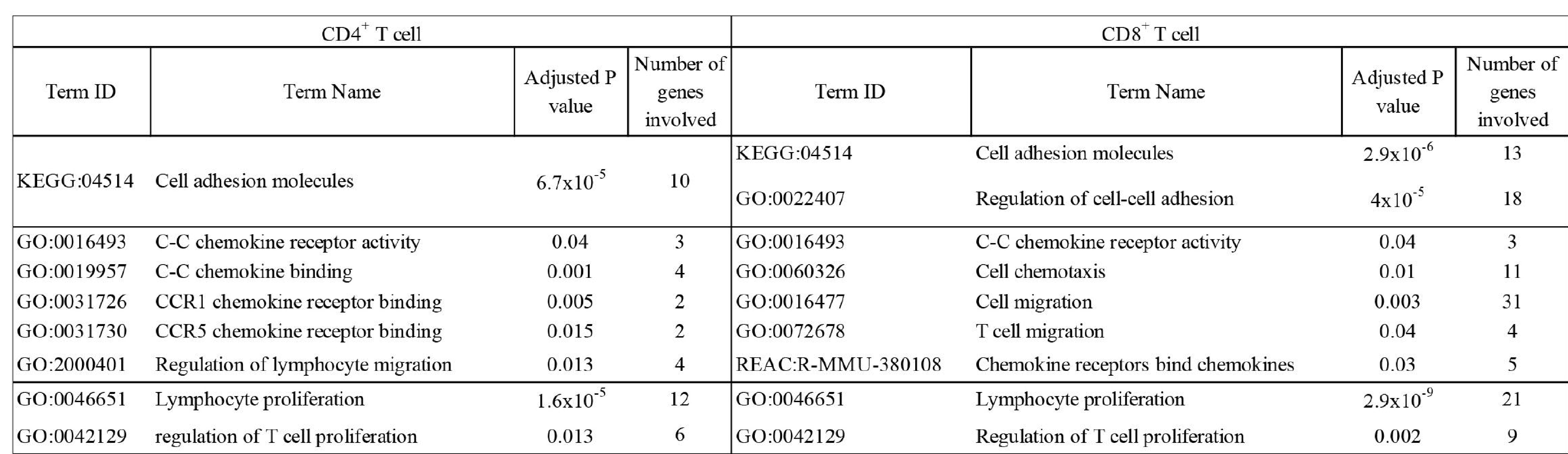

\section{Figure 6}

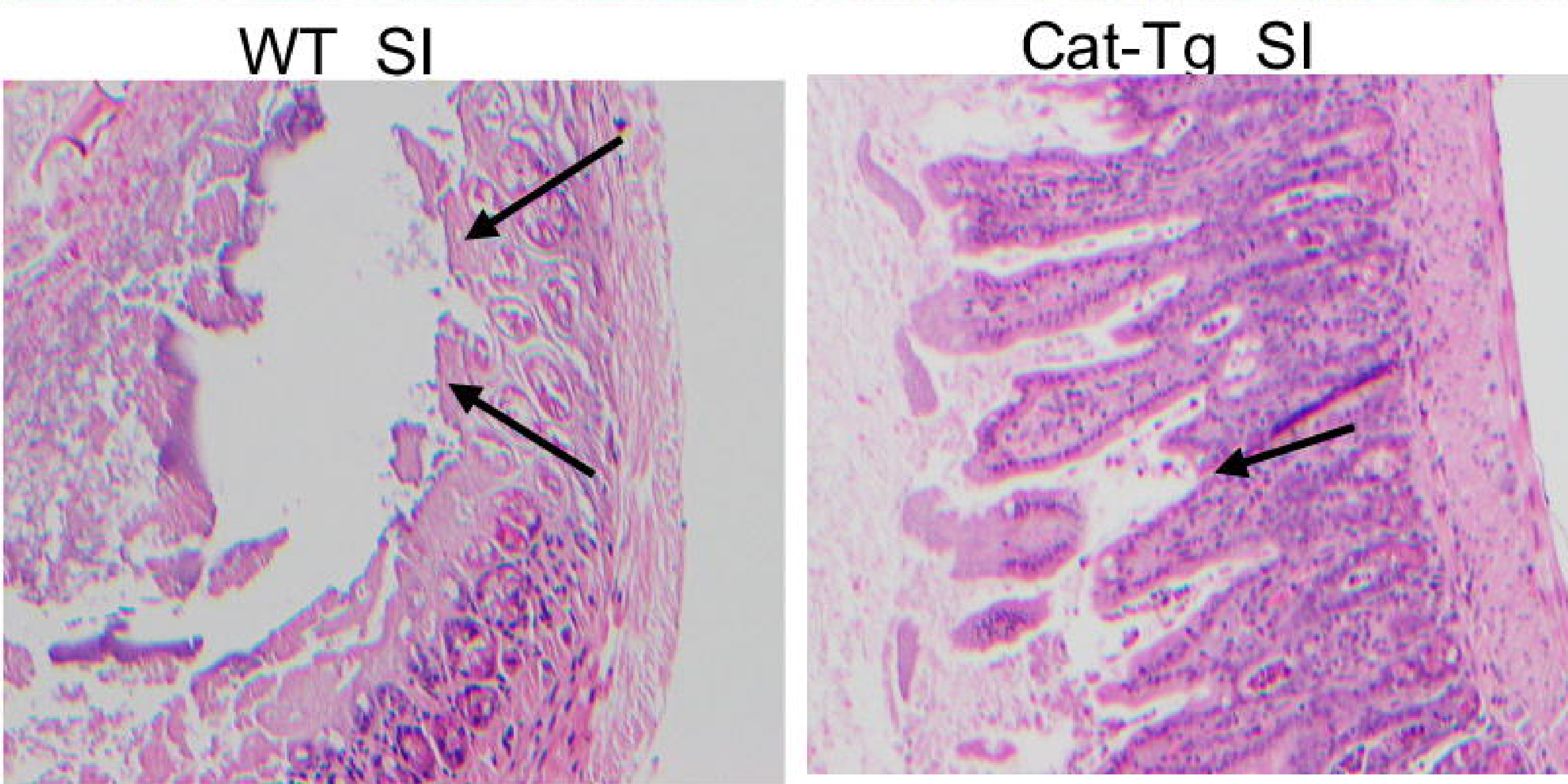

regulation of $\mathrm{T}$ cell proliferation

Regulation of $\mathrm{T}$ cell proliferation 